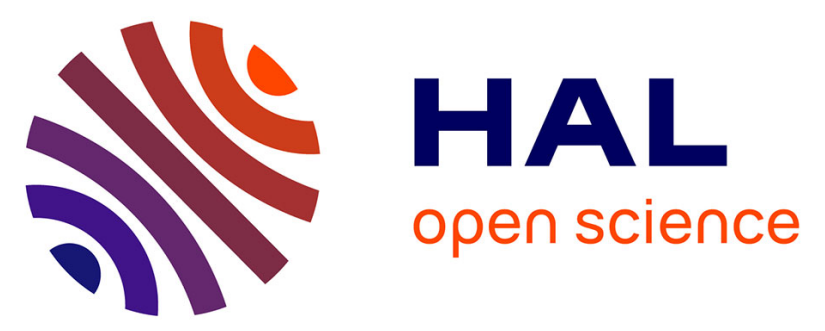

\title{
Investigation of the interface in silica-encapsulated liposomes by combining solid state NMR and first principles calculations.
}

Nicolas Folliet, Claire Roiland, Sylvie Bégu, Anne Aubert, Tzonka Mineva, Annick Goursot, Kaliaperumal Selvaraj, Luminita Duma, Frederik Tielens, Francesco Mauri, et al.

\section{To cite this version:}

Nicolas Folliet, Claire Roiland, Sylvie Bégu, Anne Aubert, Tzonka Mineva, et al.. Investigation of the interface in silica-encapsulated liposomes by combining solid state NMR and first principles calculations.. Journal of the American Chemical Society, 2011, 133 (42), pp.16815-16827. 10.1021/ja201002r . hal-00692389

\section{HAL Id: hal-00692389 \\ https://hal.science/hal-00692389}

Submitted on 23 Jan 2020

HAL is a multi-disciplinary open access archive for the deposit and dissemination of scientific research documents, whether they are published or not. The documents may come from teaching and research institutions in France or abroad, or from public or private research centers.
L'archive ouverte pluridisciplinaire HAL, est destinée au dépôt et à la diffusion de documents scientifiques de niveau recherche, publiés ou non, émanant des établissements d'enseignement et de recherche français ou étrangers, des laboratoires publics ou privés. 


\title{
Investigation of the Interface in Silica-Encapsulated Liposomes by Combining Solid State NMR and First Principles Calculations
}

Nicolas Folliet, ${ }^{+, \neq, \Delta}$ Claire Roiland, $^{+, \#, \Delta}$ Sylvie Bégu, ${ }^{\S}$ Anne Aubert, ${ }^{\S}$ Tzonka Mineva, $^{\S}$ Annick Goursot, ${ }^{\S}$ Kaliaperumal Selvaraj, ${ }^{\S, \nabla}$ Luminita Duma, ${ }^{\circ}$ Frederik Tielens, ${ }^{\ddagger}$ Francesco Mauri, ${ }^{\perp}$ Guillaume Laurent, ${ }^{\dagger}$ Christian Bonhomme, ${ }^{\dagger}$ Christel Gervais, ${ }^{\dagger}$ Florence Babonneau, ${ }^{\dagger}$ and Thierry Azaïs, ${ }^{*}$

${ }^{+}$UPMC Univ Paris 06 \& CNRS, UMR 7574, Chimie de la Matière Condensée de Paris, Collège de France, 11, place Marcelin Berthelot, F-75005, Paris, France

${ }^{\text {}}$ UPMC Univ Paris 06 \& CNRS, UMR 7197, Laboratoire de Réactivité de Surface, 4, Place Jussieu, F-75005 Paris, France

§Institut Charles Gerhardt, UMR 5253 CNRS/ENSCM/UM1, Montpellier, France

"Ecole Normale Supérieure, 24 rue Lhomond, 75231 Paris Cedex 05, France

${ }^{\perp}$ UPMC Univ Paris 06 \& CNRS, UMR 7590, Institut de Minéralogie et Physique des Milieux Condensés, 4, Place Jussieu, F-75005 Paris, France

Supporting Information

\begin{abstract}
In the context of nanomedicine, liposils (liposomes and silica) have a strong potential for drug storage and release schemes: such materials combine the intrinsic properties of liposome (encapsulation) and silica (increased rigidity, protective coating, $\mathrm{pH}$ degradability). In this work, an original approach combining solid state NMR, molecular dynamics, first principles geometry optimization, and NMR parameters calculation allows the building of a precise representation of the organic/inorganic interface in liposils. $\left\{{ }^{1} \mathrm{H}-{ }^{29} \mathrm{Si}\right\}{ }^{1} \mathrm{H}$ and $\left\{{ }^{1} \mathrm{H}-{ }^{31} \mathrm{P}\right\}{ }^{1} \mathrm{H}$ Double Cross-Polarization (CP)

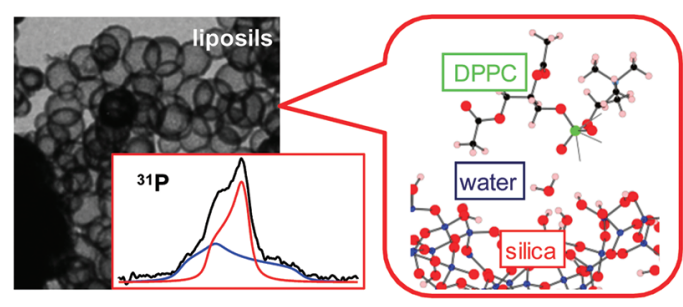
MAS NMR experiments were implemented in order to explore the proton chemical environments around the silica and the phospholipids, respectively. Using VASP (Vienna Ab Initio Simulation Package), DFT calculations including molecular dynamics, and geometry optimization lead to the determination of energetically favorable configurations of a DPPC (dipalmitoylphosphatidylcholine) headgroup adsorbed onto a hydroxylated silica surface that corresponds to a realistic model of an amorphous silica slab. These data combined with first principles NMR parameters calculations by GIPAW (Gauge Included Projected Augmented Wave) show that the phosphate moieties are not directly interacting with silanols. The stabilization of the interface is achieved through the presence of water molecules located in-between the head groups of the phospholipids and the silica surface forming an interfacial H-bonded water layer. A detailed study of the ${ }^{31} \mathrm{P}$ chemical shift anisotropy (CSA) parameters allows us to interpret the local dynamics of DPPC in liposils. Finally, the VASP/solid state NMR/ GIPAW combined approach can be extended to a large variety of organic-inorganic hybrid interfaces.
\end{abstract}

\section{INTRODUCTION}

Drug delivery is one of the major challenges in nanomedicine. ${ }^{1}$ Various approaches, including amorphous mesoporous materials, ${ }^{2}$ liposomes, ${ }^{3,4}$ and polyelectrolytes structures ${ }^{5}$ have been proposed for the diffusion and transport of bioactive cargo at predefinite targets in the cell. Recently, Brinker et al. introduced the "proto-cell" concept, corresponding to lipid bilayers onto porous silica nanoparticles (supported lipid bilayers, or SLB). ${ }^{6}$ Loading and sealing of the active cargo was achieved through the fusion of liposomes on the silica nanoparticles, leading to an efficient biocompatible vehicle. Moreover, subsequent PEGylation ${ }^{7}$ of the nanocomposites can extend the circulation time and targeting of the cells. Successive steps of lipid exchange between silica-supported bilayers and free liposomes can further reduce the bilayer defects, allowing for improved control of the nanovehicles. ${ }^{8}$

Liposomes in themselves have been extensively studied as potential drug delivery systems (either with hydrophilic or lipophilic drugs), as they offer an in vivo protection from degradative enzymes, enhanced circulation time, and bioavailability. However, such structures suffer physical instability leading to destabilization processes. ${ }^{4}$ In order to protect the fragile structure of liposomes, various strategies were recently proposed in the literature, including: silica layers ("liposil" for liposome and silica), ${ }^{9-12}$ silica nanoparticles ("SNCL" for Silica Nanoparticle Coated Liposomes), ${ }^{4}$ layers of biocompatible polyelectrolytes ("layersome"), ${ }^{5}$ selfassembled organic-inorganic shells with responsive molecular gates, ${ }^{13}$ polycationic brushes. ${ }^{14}$ Moreover, Li et al. ${ }^{15}$ proposed to use the liposomes as protective capsules for active synthesis of silica sol-gel biocomposites.

On one hand, several studies have focused on the so-called liposils where the study of the stability of loaded entities analyzed 
at different $\mathrm{pH}(1.2$ and 7.4$)$ revealed that at acidic $\mathrm{pH}$ the silica shell was stable and prevented their rapid degradation. Interestingly, at $\mathrm{pH} 7.4$ the analysis of the release kinetics of a hydrophilic drug revealed that the silica shell is hydrolyzed leading to the release of intact liposomes. ${ }^{11}$ This particular behavior make liposils potential candidates for various drug storage and release schemes in particular for oral administration as liposomes are destabilized by the acidic gastric fluid. The release of a lipophilic drug could also be induced by external stimuli, such as ultrasounds or microwaves. ${ }^{12}$ However, there is a great interest for SLBs that can be explained by their use as models for cell membranes and in biosensing devices. ${ }^{16,17}$ In SLBs, the phospholipids are expected to adsorb onto a planar substrate as a bilayer, in which the outer layer is facing the solvent while the inner layer consists of phospholipids head groups oriented toward the substrate surface. Several materials can be used as substrate: the case of silica ${ }^{18,19}$ is particularly interesting as SLBs are used as model systems to understand the mechanism of pulmonary diseases such as silicosis. ${ }^{20}$

The examples described above emphasize the crucial role of interfaces in SLBs and between the protective coatings (either organic or inorganic) and the liposomes. It follows that there is an urgent need for a detailed description and understanding of organic-inorganic interfaces in liposome-silica nanocomposites such as liposils and proto-cells. For this purpose, lipid-surface and lipid-lipid interactions, as well as possible water molecules at the interfaces, have to be taken into account (it has to be noted that the potential role of water molecules is generally underestimated). This task is obviously a major challenge as follows: (i) the quantum mechanical description of amorphous silica surfaces is still under active development; ${ }^{21,22}$ (ii) the experimental characterization of $\mathrm{OH}$ groups and adsorbed water molecules on silica surfaces remains an intense field of research; ${ }^{23,24}$ (iii) the dynamics of adsorbed species at room temperature (RT) may be taken into account for full understanding of the spectroscopic data.

Periodic plane wave DFT, as implemented in VASP (Vienna $\mathrm{Ab}$ initio Simulation Package $)^{25}$ is an efficient approach to answer the requirements of point (i). For points (ii) and (iii), solid state NMR appears as an interesting tool for the investigation of hybrid silica interfaces. ${ }^{26}$ Indeed, the chemical shifts $\left({ }^{1} \mathrm{H},{ }^{17} \mathrm{O}\right.$, ${ }^{29} \mathrm{Si}$ ) and quadrupolar parameters $\left({ }^{17} \mathrm{O}\right)$ are sensitive to chemical environments and can be modulated by local dynamics. Moreover, solid state NMR is very sensitive to internuclear distances and allows the mapping of spatial proximities between chosen nuclei. Therefore, this technique is suitable for the fine description of hybrid interfaces. However, a link between (i) and (ii), (iii) is obviously needed. It can be provided by first principles calculations of NMR parameters, starting from structural models based on DFT. For that purpose, the GIPAW (Gauge Included Projected Augmented Wave) method, first proposed by Pickard and Mauri ${ }^{27}$ is now considered as a tool of choice for solid state NMR calculations (in the frame of DFT and under periodic boundary conditions). The combined VASP/solid state NMR/ GIPAW approach seems therefore adequate for a detailed and original study and for further understanding of the liposomesilica interface at an atomic level.

In this contribution, liposils were prepared by using the sol-gel technique based on the hydrolysis and condensation of a silicon alkoxide precursor, tetraethyl orthosilicate (TEOS), ${ }^{28,29}$ in conjunction with organic templating. As a matter of fact, a large variety of self-assembled organic aggregates such as lyotropic lamellar phases and microemulsions ${ }^{30}$ can be used as potential templates. Here, a typical two-step room-temperature preparation ${ }^{31}$ has been adapted, in which the usual solution of amphiphilic moieties was replaced by small unilamellar liposomes composed of dipalmitoylphosphatidylcholine (DPPC). ${ }^{9}$ The synthesis is therefore a transcriptive templating process that results in the formation of hybrid silica nanospheres.

The first step of the combined VASP/solid state NMR/ GIPAW approach is based on the use of the amorphous silica slab model we previously developed. ${ }^{32}$ From a structural point of view, this model can be considered as safe as it describes satisfactorily: (i) the average number of surface hydroxyl groups; (ii) the chemical nature of the hydroxyl groups in terms of isolated, geminal and vicinal $\mathrm{OH}$; (iii) the main vibrational and solid state NMR data $\left({ }^{1} \mathrm{H},{ }^{29} \mathrm{Si},{ }^{17} \mathrm{O}\right)$. The model has already been considered as an interesting starting point for the study of the adsorption of amino acids. ${ }^{33}$ Here, the complex interaction between the silica slab, the adsorbed phosphatidylcholine (PC) polar head groups and eventual water molecules is taken explicitly into account in the DFT model. A realistic model for liposil is thus obtained. From a geometrical point of view, one may ask if a "planar" slab is representative of the curvature of the liposils. By simple calculations, it is clearly demonstrated that the model used corresponds to a restricted region of the whole liposil architecture. Consequently, this region can be safely represented by a plane, at least locally.

The second step of our approach deals with recent developments in solid state NMR. ${ }^{26}$ This spectroscopic technique, which is a local probe in nature, can establish proximities between nuclear spins. In that sense, solid state NMR is a perfect tool for the investigation of the hybrid organic-inorganic interfaces in nanomaterials such as liposils. The spatial proximities can be established by using the dipolar interaction through crosspolarization (CP) experiments ${ }^{34}$ (dipole-dipole coupled spins). DPPC is characterized by ${ }^{1} \mathrm{H},{ }^{13} \mathrm{C},{ }^{31} \mathrm{P}$ nuclei, whereas the silica shell is characterized by ${ }^{1} \mathrm{H}$ and ${ }^{29} \mathrm{Si}$ nuclei (protons are an obvious link between both parts). This interaction is proportional to $1 / r^{3}$ where $r$ stands for the internuclear distance. The CP approach is therefore the method of choice for distance evaluations and for the characterization of hybrid interfaces through 2D HETCOR experiments (HETeronuclear CORrelation) ${ }^{35}$ and through $\left\{{ }^{1} \mathrm{H}-{ }^{29} \mathrm{Si}\right\}{ }^{1} \mathrm{H}$ Double CP experiment. ${ }^{36-38}$ Double CP sequences are sensitive in terms of signal-to-noise ratio, as they correspond to an indirect detection $\left({ }^{1} \mathrm{H}\right)$. In particular, we show that $\left\{{ }^{1} \mathrm{H}-{ }^{29} \mathrm{Si}\right\}{ }^{1} \mathrm{H}$ combined with $\left\{{ }^{1} \mathrm{H}-{ }^{31} \mathrm{P}\right\}{ }^{1} \mathrm{H}$ experiments are efficient for editing the proximities between silanols, water molecules, and DPPC molecules, and to probe in details the silica-liposome interface.

Finally, and in order to demonstrate unambiguously the validity of the liposil model, first principles calculations of NMR parameters were performed by using GIPAW for all involved nuclei $\left({ }^{1} \mathrm{H},{ }^{29} \mathrm{Si}\right.$, $\left.{ }^{31} \mathrm{P},{ }^{17} \mathrm{O}\right)$. During recent years, it has been established that GIPAW was a reliable method of calculations in the case of crystalline organic $^{39}$ and inorganic derivatives. ${ }^{40}$ The GIPAW approach has also been successfully applied to disordered materials ${ }^{41}$ and glasses. ${ }^{42}$ Nevertheless, interfaces were rarely studied using this approach. ${ }^{43}$ More recently, the impact of local dynamics has also been considered in connection with first principles calculations. ${ }^{44}$ Here, GIPAW allows a precise assignment of the ${ }^{1} \mathrm{H}$ and ${ }^{31} \mathrm{P}$ experimental resonances obtained through Double CP experiments, providing fundamental information on the interaction of the phospholipid bilayer with the silica shell. In particular, the crucial role of interfacial water is clearly highlighted. Finally, the

${ }^{31} \mathrm{P}$ CSA tensorial parameters analysis allows us to propose a local 
dynamic model for DPPC in liposils at room temperature. Dynamics is also a fundamental ingredient of hybrid interfaces that is often neglected and that is adequately studied by the VASP/solid state NMR/GIPAW combined approach.

\section{MATERIALS AND METHODS}

Sample Preparation. ${ }^{9,10}$ The liposils synthesis follows a two-step process: first, the preparation of liposomes and then, the formation of a silica shell enclosing these liposomes. The liposomes were prepared according to the method described by Bangham. ${ }^{45}$ A suitable amount of L- $\alpha$-dipalmitoylphosphatidylcholine, DPPC (phase transition temperature $=41{ }^{\circ} \mathrm{C}$ ) is dissolved in chloroform. After complete removal of the chloroform (at $40{ }^{\circ} \mathrm{C}$ under reduced pressure), phosphate buffer solution (PBS, $150 \mathrm{mM} \mathrm{pH} \mathrm{7.4)} \mathrm{is} \mathrm{added} \mathrm{to} \mathrm{obtain} \mathrm{a} 10 \mathrm{mg} \cdot \mathrm{ml}^{-1}$ lipids suspension. This lipid suspension, containing large multilamellar vesicles, is then extruded above the transition temperature of the lipids $\left(41^{\circ} \mathrm{C}\right)$ using an extruder (Lipex biomembranes Inc.) with polycarbonate membrane (mean size diameter: 450, 200, and finally $100 \mathrm{~nm}$, Nucleopore). Liposome size determination is performed by quasi-elastic light scattering at a $90^{\circ}$ angle (SEMATECH, SM 633/RTG, France) using monomodal analysis. The mean size is determined to be $\sim 100 \mathrm{~nm}$. For the second step of the synthesis, the silica shell is obtained by adding TEOS to the liposomal suspension (TEOS:DPPC molar ratio 8:1) at room temperature and followed by stirring overnight. Sodium fluoride ( $\mathrm{NaF}$, Sigma Aldrich) at a $4 \%$ molar ratio with respect to TEOS is then added and the reaction is stirred $(48 \mathrm{~h})$ at room temperature protected from light. The sample is dried at $40^{\circ} \mathrm{C}$ for $24 \mathrm{~h}$. For further spectroscopic studies, pure DPPC and liposomes were used as reference samples.

Solid State NMR Experiments. Single pulse ${ }^{29} \mathrm{Si}$ MAS experiments were performed on an Avance 200 Bruker spectrometer (4.7 T) operating at $v_{\mathrm{L}}=39.78 \mathrm{MHz}$ using a $7 \mathrm{~mm}$ double resonance MAS probe head and a pulse of small flip angle $(\pi / 6)$. Static echo and single pulse MAS ${ }^{31} \mathrm{P}$ experiments were performed on an Avance 300 Bruker spectrometer $(7.0 \mathrm{~T})$ operating at $v_{\mathrm{L}}=121.5 \mathrm{MHz}$ using a $4 \mathrm{~mm}$ double resonance MAS probe head except for DPPC liposomes where the experiments were performed on an Avance 400 Bruker spectrometer (9.4 T; $v_{\mathrm{L}}=162 \mathrm{MHz}$ ). Single pulse ${ }^{1} \mathrm{H}$ static and MAS experiments were performed on an Avance 400 Bruker spectrometer (9.4 T) using a $4 \mathrm{~mm}$ double resonance MAS probe head. The recycle delays were 5, 10, $60 \mathrm{~s}$ for ${ }^{1} \mathrm{H},{ }^{31} \mathrm{P}$ and ${ }^{29} \mathrm{Si}$, respectively. They were adapted for allowing quantitative analysis at temperatures ranging from 275 to $323 \mathrm{~K}$. All variable temperature (VT) experiments were performed using a Bruker $\mathrm{BCU}-\mathrm{X}$ apparatus. The calibration of the temperature was performed by using $\mathrm{Pb}\left(\mathrm{NO}_{3}\right)_{2}$.

$\left\{{ }^{1} \mathrm{H}-{ }^{29} \mathrm{Si}\right\}{ }^{1} \mathrm{H}$ Double $\mathrm{CP}$ experiments were performed on an Avance 300 Bruker spectrometer $(7.0 \mathrm{~T})$ using a $4 \mathrm{~mm}$ double resonance MAS probe head. $\left\{{ }^{1} \mathrm{H}-{ }^{31} \mathrm{P}\right\}{ }^{1} \mathrm{H}$ Double CP experiments were performed on an Avance 400 Bruker spectrometer (9.4 T) using a $4 \mathrm{~mm}$ double resonance MAS probe head. The Double CP experiment ${ }^{36}$ is schematically described in Figure S1 (Supporting Information) and presents a first $\mathrm{CP}$ transfer (during $t_{\mathrm{CP}} 1$ ). Then, the magnetization of the $\mathrm{X}$ nucleus is flipped back to the $z$ direction through a $90^{\circ}$ pulse and subjected to the longitudinal relaxation time $T_{1}(\mathrm{X})$, which is much longer than the transverse relaxation time $T_{2}(\mathrm{X})$. The ${ }^{1} \mathrm{H}$ residual signal is eliminated by two low power pulses phase shifted by $90^{\circ}$ from each other at $v_{\mathrm{RF}}=v_{\mathrm{MAS}} / 2$, i.e., at the HORROR condition, thus reintroducing the homonuclear ${ }^{1} \mathrm{H}$ dipolar interaction. ${ }^{46}$ The length of each pulse corresponds to the ${ }^{1} \mathrm{H}$ FID (Free Induction Decay). This saturation step has two goals: the suppression of all unwanted ${ }^{1} \mathrm{H}$ signals and, within the model of thermal reservoirs, ${ }^{47}$ the transformation of the proton bath into a hot reservoir into which magnetization can be back-transferred from the cold reservoir composed of X nuclei. After this step, the magnetization of the $\mathrm{X}$ nucleus is flipped back into the transverse plane through a $90^{\circ}$ pulse and a second $\mathrm{CP}$ transfer is then applied (during $t_{\mathrm{CP}} 2$ ) prior to ${ }^{1} \mathrm{H}$ acquisition. For liposils sample, the MAS frequency was limited to 5 $\mathrm{kHz}$ to ensure the preservation of their fragile structure. ${ }^{1} \mathrm{H}$ detection combined with ${ }^{1} \mathrm{H}$ homonuclear decoupling has been tested but led to no significant increase in spectral resolution. To follow a possible degradation of the samples, a ${ }^{1} \mathrm{H}$ static spectrum was recorded before and after the MAS measurements and compared. Moreover, the physical integrity of the sample after solid state NMR measurements was checked by TEM (see Figure $\mathrm{S} 2$ ). $\mathrm{CDCl}_{3}$ solution ${ }^{1} \mathrm{H}$ spectrum of DPPC was performed on an Avance 300 Bruker spectrometer $(7.0 \mathrm{~T}) .{ }^{31} \mathrm{P}$ chemical shift was referenced to $85 \%$ aqueous $\mathrm{H}_{3} \mathrm{PO}_{4} \cdot{ }^{1} \mathrm{H}$ and ${ }^{29} \mathrm{Si}$ chemical shifts were referenced to TMS. Spectra deconvolutions were performed using Dmfit software. ${ }^{48}$

SEM and TEM. The morphology of liposils was investigated by conventional transmission (JEOL 1200 EXII and JEOL 1011) and scanning (Hitachi S 4500) electron microscopy's following standard sample preparation.

Computational Methods. DFT calculations were performed with the VASP (Vienna Ab initio Simulation Package) 4.6 code based on the Kohn-Sham Density Functional Theory (DFT) and using a periodic and plane-wave pseudopotential approach. Exchange-correlation was considered with the generalized gradient approximation of either Perdew-Wang ${ }^{49}$ in the case of molecular dynamics (MD) or the revised one of Perdew-Burke-Ernzerhof ${ }^{50}$ for the geometry optimizations. The integral over the first Brillouin zone was performed using a Monkhorst-Pack $1 \times 1 \times 1 k$-point grid. ${ }^{51}$ The electron-ion interaction was described by the projector augmented-wave (PAW) method. ${ }^{52}$ The interaction between the phospholipids polar head groups and the silicate surface is not expected to be significantly influenced by the hydrophobic alkyl chains and therefore, only the hydrophilic part of the phospholipids was fully considered in the various models with an aliphatic part limited to a $\mathrm{CH}_{3}$ group. Atomic positions were first relaxed using ab initio molecular dynamics within the Born-Oppenheimer approximation at constant temperature $(300 \mathrm{~K})$. The time step was set at $2.5 \mathrm{fs}$ and the geometries were sampled up to 4 ps to have a reliable image of the equilibrium geometry at $300 \mathrm{~K}$ using a microcanonical ensemble. The atomic mass of tritium has been used for all $\mathrm{H}$ atoms. Using ${ }^{3} \mathrm{H}$ for hydrogen is a standard procedure in ab initio MD to avoid too large displacements of the hydrogen atoms when large time steps are used. Increasing the mass of the atoms helps to avoid destroying the molecular structure. Since every step is very costly in this type of calculation, large time steps are needed in order to obtain a reasonable sampling time. Second, an energetically favorable geometry was picked from the MD results and optimized at $0 \mathrm{~K}$ with a $400 \mathrm{eV}$ energy cutoff.

Different configurations were built, corresponding either to a direct interaction of the phospholipid headgroup with the surface involving various $\mathrm{H}$-bonds with silanols, or to an interaction mediated by solvent molecules introduced in the calculations in order to take into account the potential role of water molecules. We considered starting points where the phospholipids head groups interact through water molecules with the silica surface involving phosphate $/ \mathrm{H}_{2} \mathrm{O}$ and $\mathrm{H}_{2} \mathrm{O}$ / silanols $\mathrm{H}$-bonds. As a first approximation, we limited the models to one or two water molecules in interaction to mimic microsolvation.

The first principles NMR calculations were performed within Kohn-Sham DFT using the PARATEC code. ${ }^{53}$ The PBE (Perdew, Burke, and Ernzerhof) generalized gradient approximation ${ }^{54}$ was used and the valence electrons were described by norm conserving pseudopotentials ${ }^{55}$ in the Kleinman-Bylander ${ }^{56}$ form. The core definition for $\mathrm{O}, \mathrm{C}$, and $\mathrm{N}$ is $1 \mathrm{~s}^{2}$ and $1 \mathrm{~s}^{2} 2 \mathrm{~s}^{2} 2 \mathrm{p}^{6}$ for $\mathrm{Si}$ and $\mathrm{P}$. The core radii are 1.2 au for $\mathrm{H}, 1.5$ au for O, 1.6 au for C, 1.8 au for Si and 2.0 au for P. The wave functions are expanded on a plane wave basis set with a kinetic energy cutoff of $1088 \mathrm{eV}$. The integral over the first Brillouin zone is performed using a Monkhorst-Pack $1 \times 1 \times 1 k$-point grid $^{51}$ for the charge density and chemical shift tensor calculation. The shielding 
tensor is computed using the GIPAW ${ }^{27}$ approach, which permits the reproduction of the results of a fully converged all-electron calculation. The isotropic chemical shift $\delta_{\text {iso }}$ is defined as $\delta_{\text {iso }}=-\left[\sigma-\sigma^{\text {ref }}\right]$ where $\sigma$ is the isotropic shielding and $\sigma^{\text {ref }}$ is the isotropic shielding of the same nucleus in a reference system as previously described. ${ }^{57,58}$ The chemical shift anisotropy $\Delta_{\mathrm{CS}}$ and asymmetry $\eta_{\mathrm{CS}}$ are defined by the following: $\Delta_{\mathrm{CS}}=\delta_{33}-\delta_{\text {iso.; }} \eta_{\mathrm{CS}}=\left(\delta_{22}-\delta_{11}\right) /\left(\delta_{33}-\delta_{\text {iso. }}\right)$ with $\delta_{\text {ii }}$ corresponding to the chemical shift principal values and $\left|\delta_{33}-\delta_{\text {iso }}\right| \geq$ $\left|\delta_{11}-\delta_{\text {iso }}\right| \geq\left|\delta_{22}-\delta_{\text {iso }}\right|$.

\section{RESULTS}

TEM micrograph of liposils (Figure 1a) shows nanocapsules with a mean diameter close to the unilamellar liposomes one $(105 \mathrm{~nm})$. The silica wall thickness of these nanocapsules is estimated to be 6 to $9 \mathrm{~nm}$ from TEM. Previous studies through fluorescence anisotropy measurements demonstrated that the bilayer organization of DPPC in liposils is preserved ${ }^{9}$ (Figure $1 \mathrm{~b}$ ). In the synthesis of liposils, DPPC's liposomes are acting as templates for the sol-gel polymerization of silica. It implies that a specific interaction should exist between liposomes and the siliceous species. Otherwise, it would lead to a phase separation of silica which is not observed by SEM ${ }^{10}$ (Figure S3 of the SI).

Solid State NMR Investigation of the Silica/Liposome Interface. Single pulse MAS ${ }^{29} \mathrm{Si}$ NMR spectrum (Figure S4a of the SI) was recorded in order to estimate the extent of condensation of the silica shell. This spectrum shows the three characteristic resonances of amorphous silica located at $-90 \mathrm{ppm}$ $\left(Q_{2}-13 \%\right),-101 \mathrm{ppm}\left(Q_{3}-39 \%\right)$ and $-111 \mathrm{ppm}\left(Q_{4}-\right.$ $48 \%))$. The relative amount of $Q_{4}$ units indicates that the silicate network is well condensed although the sol-gel synthesis was performed in particularly dilute condition at neutral $\mathrm{pH}$ but with a nucleophilic catalyst $\left(F^{-}\right)$. Nevertheless, the ratios of $Q_{2}$ and $Q_{3}$ units (usually surface species) lead to a non negligible concentration of silanols $(\mathrm{SiOH})$. As already reported above, we note that according to SEM pictures, residual silica is not significantly dominant in the sample (Figure S3 of the SI).

We further focus on the investigation of the phospholipids to study the influence of the silica shell on coated liposomes. The ${ }^{31} \mathrm{P}$ MAS NMR spectrum of liposils displays one isotropic and symmetric resonance located at $-0.7 \mathrm{ppm}(\mathrm{LW}=3.8 \mathrm{ppm})$ characteristic of a phosphate unit (Figure S4b of the SI). For comparison purposes, we also studied an aqueous suspension of DPPC liposomes. A resonance at a similar chemical shift value $(-0.8 \mathrm{ppm})$ is observed (Figure S4c of the SI). It is well-known that the measurement of the ${ }^{31} \mathrm{P}$ chemical shift anisotropy (CSA) tensor parameters is very informative on the dynamics of the lipid phosphate head groups. ${ }^{59}$ We used aqueous DPPC liposomes and DPPC powder as reference samples having different surroundings and dynamics. ${ }^{31} \mathrm{P}$ CSA measurements were performed through static and slow MAS ${ }^{31} \mathrm{P}$ and ${ }^{1} \mathrm{H}-{ }^{31} \mathrm{P} \mathrm{CP}$
MAS NMR. The corresponding spectra are depicted in Figure 2 for DPPC aqueous liposomes, dry DPPC and liposils. We observe typical CSA lineshapes for each sample. Dry DPPC displays the broadest static spectrum whereas DPPC aqueous liposomes exhibits the smallest line width. Liposils display a slightly lower broadening compared to dry DPPC that is estimated by the determination of the CSA parameters ${ }^{60}$ as shown in Figure S5 of the SI $\left(\Delta_{\mathrm{CS}}=-110.0,-99.5\right.$, and $35.0 \mathrm{ppm}$ for dry DPPC, liposils, and DPPC aqueous liposomes, respectively-Table 1). The asymmetry parameters $\eta_{\mathrm{CS}}$ are equivalent for liposils and dry DPPC $(\sim 0.6)$, whereas DPPC aqueous liposomes exhibit an axial CSA tensor $\left(\eta_{\mathrm{CS}}=0\right)$ in agreement with previous values already published in the literature. ${ }^{61}$

According to the representation of liposils described in Figure $1 \mathrm{~b}$, two ${ }^{31} \mathrm{P}$ components are expected. Indeed, the liposils entities contain two types of lipids: half face the silica surface, the other half face bulk-like liquid water (at the center of the liposil). From Figure $2 \mathrm{f}$ (obtained with CP experiments), a single set of CSA parameters is extracted, in apparent contradiction with our expectations. In order to clarify this particular point, we performed variable temperature (VT) experiments (Figure 3a). These experiments correspond to direct ${ }^{31} \mathrm{P}$ detection, without $\mathrm{CP}$ from ${ }^{1} \mathrm{H}$ to ${ }^{31} \mathrm{P}$. At low temperature, a unique CSA line shape is observed. An increase in temperature leads to the observation of a second component with reduced CSA parameters. The simulation of the total line shape using two components with identical $\delta_{\text {iso. }}\left({ }^{31} \mathrm{P}\right)(-0.7 \mathrm{ppm})$ but different CSA parameters (site 1 , $\Delta_{\mathrm{CS}}=-105 \mathrm{ppm}, \eta_{\mathrm{CS}}=0.5$; site $\left.2, \Delta_{\mathrm{CS}}=35 \mathrm{ppm}, \eta_{\mathrm{CS}}=0.3\right)$ is presented in Figure $3 \mathrm{~b}$ (for $T=313 \mathrm{~K}$ ). Moreover, all static spectra can be simulated by using these components and by varying only the intensities (all CSA parameters kept fixed). The quantification of the two CSA tensors versus temperature is given in Figure 3c. A smooth transition is evidenced and can be compared to the one observed for liposils by fluorescence anisotropy. ${ }^{10}$ For $T \geq 310 \mathrm{~K}$, the populations of site 1 and 2 are $\sim 50 \%$. At this stage, several comments can be made. First, the same VT experiments were performed under moderate MAS, without CP (see Figure S6 of the SI). As a matter of fact, it is impossible to distinguish two $\delta_{\text {iso. }}\left({ }^{31} \mathrm{P}\right)$, taking into account the natural line width of the resonance. However, the shape of the spinning sidebands pattern is sensitive to temperature, demonstrating that two components with different sets of CSA parameters have to be considered. Most importantly, VT static echo experiments were recorded using ${ }^{1} \mathrm{H}-{ }^{31} \mathrm{P} \mathrm{CP}$ (Figure $\mathrm{S} 7$ of the $\mathrm{SI})$ : in that case, the contribution of site 2 is systematically underestimated (the contribution is hardly discernible even by looking carefully at the spectra).

We can now interpret the experimental results taking into account the two types of lipids described above. At low temperature, the dynamics are highly restricted for both types of lipids and the corresponding CSA parameters are equivalent $\left(\Delta_{\mathrm{CS}}=-105 \mathrm{ppm}, \eta_{\mathrm{CS}}=0.5\right.$, Figure $\left.3 \mathrm{a}, T=275 \mathrm{~K}\right)$. As temperature is increasing, there is a change of the dynamics of the lipid headgroups at the bulk-like water interface (site 2). The lipids facing the silica surface remain rigid (site 1). It is interesting to note that the CSA parameters for site $2\left(\Delta_{\mathrm{CS}}=35 \mathrm{ppm}, \eta_{\mathrm{CS}}=\right.$ 0.3 ) are closely related to those observed for aqueous liposomes and the CSA parameters for site 1 are similar to those obtained at RT through CP MAS (Figure 2 and Table 1). The discrepancy between $\eta_{\text {CS }}$ values is not crucial as correct simulations of the VT spectra were also obtained by fixing $\eta_{\mathrm{CS}}=0.6$ and 0.0 for site 1 and site 2 , respectively (see Figure S8 of the SI). The $\delta_{\text {iso. }}\left({ }^{31} \mathrm{P}\right)$ 
Table 1. ${ }^{31}$ P CSA Tensorial Parameters for Dry DPPC, Liposils and DPPC Aqueous Liposomes ${ }^{a}$

\begin{tabular}{|c|c|c|c|c|c|c|}
\hline & $\delta_{\text {iso }}(\mathrm{ppm})$ & $\delta_{11}(\mathrm{ppm})$ & $\delta_{22}(\mathrm{ppm})$ & $\delta_{33}(\mathrm{ppm})$ & $\Delta_{\mathrm{CS}}(\mathrm{ppm})$ & $\eta_{\mathrm{CS}}$ \\
\hline DPPC aqueous liposome & -0.8 & -16.2 & -16.2 & 36.3 & 35.0 & 0.0 \\
\hline Dry DPPC & -2.1 & 83.5 & 22.9 & -111.7 & -110.0 & 0.6 \\
\hline liposils & -0.7 & 78.8 & 19 & -100.2 & -99.5 & 0.6 \\
\hline
\end{tabular}

${ }^{a}$ These values were obtained by fitting the ${ }^{31} \mathrm{P}$ slow MAS and static NMR spectra shown in Figure . Chemical shielding principal values $\delta_{11}, \delta_{22}$, $\delta_{33}$ were ordered as follows: $\left|\delta_{33}-\delta_{\text {iso }}\right| \geq\left|\delta_{11}-\delta_{\text {iso }}\right| \geq\left|\delta_{22}-\delta_{\text {iso }}\right|$. The other parameters were defined as follows: $\delta_{\text {iso }}=1 / 3\left(\delta_{11}+\delta_{22}+\delta_{33}\right)$; $\eta_{\mathrm{CS}}=\left(\delta_{22}-\delta_{11}\right) /\left(\delta_{33}-\delta_{\text {iso }}\right) ; \Delta_{\mathrm{CS}}=\delta_{33}-\delta_{\text {iso }}\left(\delta_{\text {ii }} \pm 0.5 \mathrm{ppm}, \eta_{\mathrm{CS}} \pm 0.15\right)$.

are comparable: indeed, it is well-known that $\delta_{\text {iso. }}\left({ }^{31} \mathrm{P}\right)$ is mainly sensitive to the closest atoms, i.e., water molecules for both types of phosphates of the lipid headgroup. However, $\Delta_{C S}\left({ }^{31} \mathrm{P}\right)$ is the pertinent parameter to distinguish them, as soon as the dynamics of DPPC is allowed. The transition is smooth as shown in Figure $3 \mathrm{c}$. For $T \geq 310 \mathrm{~K}$, equal populations for site 1 and site 2 are observed, as expected.

Two experimental facts must be emphasized: (i) MAS experiments are not suitable for the clear distinction between sites 1 and 2 (Figure S6 of the SI); (ii) CP static experiments are not suitable as well (Figure $\mathrm{S} 7$ of the SI). Site 2 is underestimated due to dynamics, leading probably to an efficient averaging of the ${ }^{1} \mathrm{H}-{ }^{31} \mathrm{P}$ and ${ }^{1} \mathrm{H}-{ }^{1} \mathrm{H}$ dipolar interactions. It explains why a unique component is observed in Figure $2 \mathrm{f}$ ( $C P$ static echo experiment) corresponding to site 1 , exclusively.

Finally, and in order to confirm the assumption made above, ${ }^{31} \mathrm{P}$ static echo experiments (without $C P$ ) were performed on a dehydrated liposils sample (in that particular case, the bulk-like liquid water is absent, leading to "dry DPPC-like" liposils. The static ${ }^{1} \mathrm{H}$ NMR spectrum is also presented in Figure S9 (insert) of the SI. The simulation of the line shape is performed by using two components for DPPC (aliphatic chain and choline/glycerol neck/ethylene). No contribution of water can be detected (see below for the simulation of the ${ }^{1} \mathrm{H}$ spectra). As expected, and in full agreement with the structural assumptions, site 2 contribution is not detected in the $\mathrm{VT}^{31} \mathrm{P}$ spectra.

In order to get a more complete description of the silica/ liposome interface, the study was completed with ${ }^{1} \mathrm{H}$ solid state NMR measurements. Figure S10a of the SI displays the static ${ }^{1} \mathrm{H}$ NMR spectrum of liposils and shows a broad resonance at 0.9 ppm assigned to the alkyl chain of lipids and a sharper resonance at $4.2 \mathrm{ppm}$ which corresponds to free water. The ${ }^{1} \mathrm{H}$ MAS spectrum (Figure $4 \mathrm{a}$ and $\mathrm{S} 10 \mathrm{~b}$ of the SI), recorded at $v_{\text {MAS }}=$ $5 \mathrm{kHz}$, displays an increased resolution for the lipids proton resonances, with two peaks now observed at 1.2 and $0.8 \mathrm{ppm}$ $\left(\mathrm{CH}_{2}\right.$ and $\mathrm{CH}_{3}$ groups of the alkyl chains, respectively). The water resonance line width decreases from 2.0 to $1.5 \mathrm{ppm}$ (it has to be noted that higher MAS frequency was not implemented in order to keep intact the fragile structure of the liposils_-see the Experimental Section). The simulation of the static spectra was performed as indicated in Figure S9 of the SI. We define the fill factor of the liposils by the following ratio: $f=n_{\mathrm{H} 2 \mathrm{O}-\text { liposils }} /$ $n_{\mathrm{H} 2 \mathrm{O}-\text {-aq.liposome, }}$ where $n_{\mathrm{H} 2 \mathrm{O}-\text { liposils }}$ stands for the water molecules per DPPC molecule and $\mathrm{n}_{\mathrm{H} 2 \mathrm{O} \text {-aq.liposome }}\left(\sim 155 \mathrm{H}_{2} \mathrm{O} / \mathrm{DPPC}\right)$ corresponds to the aqueous liposome case. ${ }^{10}$ In the present case, and as a rough approximation, the area of ${ }^{1} \mathrm{H}$ resonance from $\mathrm{DPPC} \approx 25 \%$ and from water $\sim 75 \%$. It follows that $1 \mathrm{DPPC}$ molecule is associated to $\sim 85 \mathrm{H}_{2} \mathrm{O}$ molecules, leading to $f \approx 55 \%$ (in the case of the dehydrated liposils, Figure S9 of the SI, $f \approx 0 \%$ ).

The ${ }^{1} \mathrm{H}$ solution NMR spectrum of DPPC (in $\mathrm{CDCl}_{3}$ ) is shown in Figure 4b. Its full assignment was performed thanks to ${ }^{1} \mathrm{H}-{ }^{1} \mathrm{H}$ COSY experiments (Figure $\mathrm{S} 11$ of the SI) and comparison to previous data published in the literature. ${ }^{62}$ Peaks located between 0 and $3 \mathrm{ppm}$ are attributed to the alkyl chain (peaks named A, B, C, and D). A peak located at $3.3 \mathrm{ppm}$ corresponds to protons of the choline headgroup (peak J). Between 3.5 and 5.5 $\mathrm{ppm}$ we observe the proton resonances characteristic of the glycerol neck (peaks E, F, and G) and the ethylene moiety (peaks $\mathrm{H}$ and I). According to these data, the liposil ${ }^{1} \mathrm{H}$ MAS spectrum can now be described as follows (Figure 4a): a broad resonance located around $4.2 \mathrm{ppm}$ which corresponds mainly to water and overlaps with the E, F, G, H, and I proton signals, a shoulder located at $3.3 \mathrm{ppm}$ corresponding to the DPPC's choline group (protons $\mathrm{J}$ ), and two sharper resonances at 0.8 and $1.2 \mathrm{ppm}$ attributed to the protons of the alkyl chains of DPPC (protons A to D). A much less intense peak can be observed at $\sim 7 \mathrm{ppm}$ (Figure $\mathrm{S} 10$ of the SI). It can be tentatively assigned to $\mathrm{Si}-\mathrm{OH}$ groups or strongly H-bonded water molecules (see below).

To further investigate the interface between silica and DPPC moieties, spatial proximities have to be established between ${ }^{29} \mathrm{Si}$ nuclei and the protons of DPPC and eventual water molecules located at the hybrid interface. 2D $\left\{{ }^{1} \mathrm{H}\right\}{ }^{29} \mathrm{Si}$ HETCOR experiment is a standard solid state NMR technique that is widely used to probe the proximities in hybrid silica materials. However, this technique suffers from low sensitivity due to the relatively low $\gamma$ of the ${ }^{29} \mathrm{Si}$ nucleus combined with the broadness of the amorphous silica ${ }^{29} \mathrm{Si} \mathrm{signals.} 48 \mathrm{~h}$ are generally necessary to record a 2D $\left\{{ }^{1} \mathrm{H}\right\}^{29}$ Si HETCOR experiment with a reasonable signal-tonoise ratio $(\mathrm{S} / \mathrm{N})$ at moderate field. Furthermore, in order to maximize $\mathrm{S} / \mathrm{N}$, the contact time $t_{\mathrm{CP}}$ needs to be set to several ms leading to the investigation of relatively long distances. In order to explore shorter distances (few $\AA$ ) that give precise information about the silica interface, $t_{\mathrm{CP}}$ needs to be on the order of hundreds of $\mu \mathrm{s}$, which leads to even longer experiments for a given $S / N$ ratio. In order to overcome this problem, we used $\left\{{ }^{1} \mathrm{H}-{ }^{29} \mathrm{Si}\right\}{ }^{1} \mathrm{H}$ double $\mathrm{CP}$ experiments in order to detect the high- $\gamma$ nucleus (inverse detection). ${ }^{36}$ Such an approach is not new in the literature but it was mainly used to select and enhance signals from specific rare nuclei $\left({ }^{13} \mathrm{C},{ }^{15} \mathrm{~N}\right)$ in biochemical compounds. ${ }^{63}$ The first contact time $\left(t_{\mathrm{CP}} 1\right)$ is set to optimize the ${ }^{29} \mathrm{Si}$ signal intensity, whereas the second one $\left(t_{\mathrm{CP}} 2\right)$ is incremented to probe spatial proximities. Spectra with high $S / N$ are usually recorded in $1 \mathrm{~h}$ (leading to a great experimental time saving compared to standard 2D $\left\{{ }^{1} \mathrm{H}{ }^{29}\right.$ Si HETCOR experiments). Most importantly, such experiments lead to the progressive spectral edition of protons, starting from the silica surface. The description of protons in close proximity to the surface becomes possible (in contrast to standard ${ }^{1} \mathrm{H}$ 1D MAS experiments, where such contributions are 
hardly discernible). The 1D $\left\{{ }^{1} \mathrm{H}-{ }^{29} \mathrm{Si}\right\}{ }^{1} \mathrm{H}$ Double CP spectra of liposils recorded with $t_{\mathrm{CP}} 2$ ranging from $500 \mu$ s to $20 \mathrm{~ms}$ are shown in Figure 5 for $t_{C P} 1=3 \mathrm{~ms}$. At short contact time $\left(t_{C P} 2=\right.$ $1 \mathrm{~ms}$ ), two resonances appear on the spectrum: a broad one located at $\sim 6.8 \mathrm{ppm}$ and another one at $4.2 \mathrm{ppm}$, respectively. According to previous data, ${ }^{24,32,36,64}$ the first peak $(6.8 \mathrm{ppm})$ can be assigned to silanols and/or water exhibiting strong hydrogen bonding, whereas the second peak $(4.2 \mathrm{ppm})$ arises in the region of water (less hydrogen bonded), DPPC's glycerol neck (E, F, G) and DPPC's ethylene protons (H, I). It can be emphasized that the contribution at $6.8 \mathrm{ppm}$ is clearly evidenced by the Double $\mathrm{CP}$ experiments at short $t_{\mathrm{CP}} 2$. This contribution is hardly discernible in the ${ }^{1} \mathrm{H}$ single pulse MAS spectrum. At this stage, we note that silanols and water molecules can be located both on the outer surface of the silica shell and at the interface with liposomes. Interestingly, the resonances corresponding to the phospholipids become predominant when increasing $t_{\mathrm{CP}} 2$. In particular, at longer contact time $\left(t_{\mathrm{CP}} 2=4 \mathrm{~ms}\right)$, a resonance at 1.3 ppm is visible that corresponds to the $\mathrm{CH}_{2}$ moieties of the alkyl chains. A close analysis of the ${ }^{1} \mathrm{H}$ spectrum recorded at moderate contact time $\left(t_{\mathrm{CP}} 2=1 \mathrm{~ms}\right)$ evidence also a significant shoulder at $3.3 \mathrm{ppm}$ corresponding to the choline headgroup. Therefore, the close proximity of the silica shell with the DPPC molecules (and in particular with the lipid's polar headgroup and the glycerol neck) is evidenced.

The Double CP experiments were extended to the ${ }^{1} \mathrm{H}-{ }^{31} \mathrm{P}$ spin pair. $\left\{{ }^{1} \mathrm{H}-{ }^{31} \mathrm{P}\right\}{ }^{1} \mathrm{H}$ Double $\mathrm{CP}$ spectra of liposils obtained with $t_{\mathrm{CP}} 2$ ranging from $100 \mu$ s to $5 \mathrm{~ms}$ are shown in Figure 6. At short contact time $\left(100 \mu \mathrm{s} \leq t_{\mathrm{CP}} 2 \leq 500 \mu \mathrm{s}\right)$, a broad resonance from 6 to $12 \mathrm{ppm}$ and centered at $\sim 7.8 \mathrm{ppm}$ is detected together with two sharper signals at $4.2 \mathrm{ppm}$ and $3.3 \mathrm{ppm}$. As $t_{\mathrm{CP}} 2$ increases, the intensity of the two latter signals increases and at $\mathrm{t}_{\mathrm{CP}} 2=5 \mathrm{~ms}$ a resonance at $1.3 \mathrm{ppm}$ appears. Straightforwardly, the resonances at $1.3,3.3$, and $4.2 \mathrm{ppm}$ should correspond to the DPPC molecules, precisely to the alkyl chains $(A-D)$, the choline headgroup (J) and the glycerol neck (E, F, G) together with the ethylene moiety $(\mathrm{H}, \mathrm{I})$, respectively. As in the case of $\left\{{ }^{1} \mathrm{H}-{ }^{29} \mathrm{Si}\right\}{ }^{1} \mathrm{H}$ Double $\mathrm{CP}$ experiments, a broad deshielded component is observed at short $t_{\mathrm{CP}} 2$ that does not correspond to any protons of the DPPC molecules. Nevertheless, one notes a small variation of the maximum of the line from 6.8 to $7.8 \mathrm{ppm}$. The signal located at $6-9 \mathrm{ppm}$, similar to the resonance detected through the silicon-filtered experiment, should correspond to $\mathrm{H}$-bonded $\mathrm{SiOH} /$ water molecules ${ }^{65}$ at the interface between silica and the DPPC phosphate groups. As $t_{\mathrm{CP}} 2$ values are short, the involved protons correspond to the closest neighbors of the ${ }^{29} \mathrm{Si}$ and ${ }^{31} \mathrm{P}$ nuclei. For longer $t_{\mathrm{CP}} 2$, the progressive edition of the lines $(4.2,3.3$, and $1.3 \mathrm{ppm})$ is similar to that already obtained for $\left\{{ }^{1} \mathrm{H}-{ }^{29} \mathrm{Si}\right\}{ }^{1} \mathrm{H}$ Double CP experiments.

As a partial conclusion, we have demonstrated that $\left\{{ }^{1} \mathrm{H}-{ }^{29} \mathrm{Si} /{ }^{31} \mathrm{P}\right\}{ }^{1} \mathrm{H}$ Double $\mathrm{CP}$ experiments were sensitive to protons at the interface. The detected broad signals around 6-9 ppm can be assigned to silanols and/or water molecules that are part of an interfacial H-bonded layer between the outer phosphate groups and the $\mathrm{SiOH}$ groups of the silica surface. The assumption concerning the silica/DPPC interaction must be now validated, starting from a realistic DFT model.

Toward a Realistic Model for the Silica/Liposome Interface. The silica/liposome interface was investigated through DFT geometry optimization of the adsorption of the hydrophilic phosphatidylcholine (PC) headgroup of the phospholipid on a previously modeled amorphous silica surface. ${ }^{32}$ The starting point of the PC structure for the modeling of the adsorption was chosen from the most stable DPPC conformers calculated by Goursot and co-workers using DFT, augmented with a damped empirical dispersion energy term (DFT-D). ${ }^{66}$ Four energetically favorable structures are presented in Figure 7: two of them correspond to a direct interaction of the PC headgroup with the surface (configurations I and II) while the remaining two conformations include two or one water molecules (configurations III and IV respectively) at the interface between the phospholipids and the surface silanols. For configurations I and II (Figure 7a and 7b), we found that PC is mainly in interaction with the surface through $\mathrm{H}$ bonding between the phosphate group and silanols. These findings are in good agreement with previous data recently reported in the literature ${ }^{67}$ where $\mathrm{ab}$ initio DFT calculations were conducted on clusters constructed with small representative parts of the silica surface and a PC headgroup (one or two silica tetrahedral units). The authors concluded on a strong interaction between the phosphate group and silanols through $\mathrm{H}$ bonding. Interestingly, in configurations III and IV, PC is stabilized through water molecules located in-between the phosphate moiety and the silica surface (Figure $7 \mathrm{c}$ and $7 \mathrm{~d}$ ). The oxygen of the $\mathrm{PO}_{4}$ group, the water molecules and the silanols lead to the following $\mathrm{H}$-bond network: $\mathrm{O}_{3} \mathrm{P}-\mathrm{O} \bullet \bullet \bullet \mathrm{H}_{2} \mathrm{O} \bullet \bullet \mathrm{HOSi}$. Note that the number of $\mathrm{H}$-bonds involved with the phosphate group decreases from 4 to 1 in the various configurations (from I to IV). Moreover, no particular interaction between the choline moiety and $\mathrm{SiOH}$ is found in any of the studied configurations.

Validation of the Modeling for Liposils. Corresponding NMR parameters were also calculated (Table 2) by GIPAW for comparison to experimental ones (protons strongly interacting with the phosphate moiety are labeled $\mathrm{H} 1$ to $\mathrm{H} 6$, see Figure 7). We first consider the calculated ${ }^{1} \mathrm{H}$ isotropic chemical shifts $\left(\delta_{\text {iso. }}\left({ }^{1} \mathrm{H}\right)\right)$. Table 2 gives also the shortest $\mathrm{OH} \bullet \bullet \mathrm{O}$ distances for a given proton. Indeed, it has been already reported that $\delta_{\text {iso. }}\left({ }^{1} \mathrm{H}\right)$ was highly sensitive to hydrogen bonding: ${ }^{44 \mathrm{~b}}$ $\delta_{\text {iso. }}\left({ }^{1} \mathrm{H}\right)$ strongly increases with decreasing of $\mathrm{OH} \bullet \bullet \bullet \mathrm{O}$ hydrogen bond length. When $\mathrm{OH} \bullet \bullet \bullet-1.90 \AA$ ( $\mathrm{OH}$ groups and water molecules exhibiting strong $\mathrm{H}$ bonding), calculated $\delta_{\text {iso.- }}$. $\left({ }^{1} \mathrm{H}\right)$ are in the range $8-5 \mathrm{ppm}$. For more "isolated" $\mathrm{OH}$ groups $(\mathrm{OH} \bullet \bullet \mathrm{O} \geq 1.90 \AA)$, the proton resonances are obviously shielded (down to $\sim 3 \mathrm{ppm}$ ). It has to be noticed that the accuracy of the ${ }^{1} \mathrm{H}$ GIPAW calculations can be estimated to \pm 0.3 ppm. ${ }^{68}$ Such results are not in contradiction with the experimental data. ${ }^{29} \mathrm{Si}$ and ${ }^{31} \mathrm{P}$ Double $\mathrm{CP}$ experiments clearly revealed deshielded components at $\sim 6-9 \mathrm{ppm}$. Moreover, a resonance located at $4.2 \mathrm{ppm}$ assigned to less bonded water molecules and/ or more isolated $\mathrm{OH}$ groups was also evidenced. Nevertheless, the calculated $\delta_{\text {iso. }}\left({ }^{1} \mathrm{H}\right)$ data are not sufficient to discriminate between the configurations presented in Figure 7, when compared to the experimental data.

The calculated $\delta_{\text {iso. }}\left({ }^{31} \mathrm{P}\right)$ data are particularly informative. It is shown in Table 2 that a clear decrease of $\delta_{\text {iso. }}\left({ }^{31} \mathrm{P}\right)$ is observed from configuration I to configuration IV (the accuracy of ${ }^{31} \mathrm{P}$ calculations is estimated to $\pm 0.7 \mathrm{ppm}) .{ }^{69}$ The experimental data $(\delta \approx-0.7 \mathrm{ppm})$ are in favor of configuration IV, involving a water molecule and a single $\mathrm{H}$ bond. The ${ }^{31} \mathrm{P}$ MAS line width 
Table 2. Calculated and Experimental (Only for $\left.{ }^{31} \mathbf{P}\right){ }^{1} \mathrm{H}$ and ${ }^{31} \mathbf{P}$ Isotropic Chemical Shifts, $\delta_{\text {iso., }}$ for the Liposils and the Modelled Configurations I to IV (see Figure 6 for the Labelling of the Protons) ${ }^{a}$

\begin{tabular}{|c|c|c|c|c|c|c|c|c|c|}
\hline \multirow[t]{2}{*}{ site } & $\exp$ & \multicolumn{2}{|c|}{ config. I } & \multicolumn{2}{|c|}{ config. II } & \multicolumn{2}{|c|}{ config. III } & \multicolumn{2}{|c|}{ config. IV } \\
\hline & $\delta_{\text {iso }}(\mathrm{ppm})$ & $\delta_{\text {iso }}(\mathrm{ppm})$ & $\underset{\text { OH. }}{\text { distance }}(\stackrel{\mathrm{O}}{(\AA)})$ & $\delta_{\text {iso }}(\mathrm{ppm})$ & $\underset{\text { OH. }}{\text { distance }} \cdot \underline{(\AA)}$ & $\delta_{\text {iso }}(\mathrm{ppm})$ & $\underset{\text { OHstance }}{\mathrm{O}} \cdots \underline{\mathrm{O}}$ & $\delta_{\text {iso }}(\mathrm{ppm})$ & 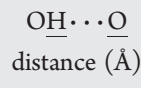 \\
\hline $\mathrm{P}$ & -0.7 & 6.8 & & 4.9 & & 4.4 & & -0.3 & \\
\hline $\mathrm{H} 1$ & & 8.1 & 1.65 & 6.3 & 1.79 & 3.0 & 2.19 & 5.6 & 1.91 \\
\hline $\mathrm{H} 2$ & & 5.8 & 1.84 & 6.0 & 1.75 & 4.7 & 1.92 & 5.4 & 1.88 \\
\hline $\mathrm{H} 3$ & & 6.6 & 1.83 & 5.2 & 1.90 & 6.5 & 1.80 & & \\
\hline $\mathrm{H} 4$ & & 3.3 & 2.09 & & & 4.4 & 1.93 & & \\
\hline H5 & & & & & & 6.6 & 1.73 & 6.5 & 1.80 \\
\hline H6 & & & & & & 6.4 & 1.80 & & \\
\hline
\end{tabular}

${ }^{a}$ The shortest $\mathrm{OH} \cdots \mathrm{O}$ distances are also given ( $\mathrm{H}$ bond networks).

(i.e., $3.8 \mathrm{ppm}$ ) can be explained by a distribution of chemical shifts, related to conf. IV-like chemical environments (and probably conf. III-like also). Configurations I and II, involving 4 and 3 $\mathrm{H}$-bonds, respectively, but no water molecule can be safely excluded on the basis of ${ }^{31} \mathrm{P}$ GIPAW calculations. Indeed, if there had been a direct $\mathrm{PC} /$ silica interaction, without any water molecules at the interface, two ${ }^{31} \mathrm{P}$ resonances with two distinct chemical shifts corresponding to the inner and the outer lipid layer should have been observed (provided that the corresponding line widths would have been sharp enough). It follows that the lipid bilayers are stabilized at the silica surface through a very thin water hydration layer which ensures the cohesion of the nanocomposite. This result is in good agreement with previous data published in the literature where neutron scattering experiments ${ }^{70}$ and molecular dynamics simulation ${ }^{71}$ revealed that the interface water layer of POPC (palmitoyl-oleyl-snphosphatidyl-choline) single bilayer deposited on amorphous silica is very thin: bound water molecules hydrating the lipid head groups and the hydrophilic silica surface were observed. Very recently, the investigation of DOPC (Dioleoylphosphatidylcholine) bilayer adsorbed onto silica by dual polarization interferometry combined to quartz-crystal microgravimetry revealed a thickness of the hydration layer around $10.2 \AA^{72}$ In the case of Configuration IV, the distance between the phosphate headgroup and the silica surface can be estimated to $\sim 5 \AA$ which suggests that DPPC bilayers might be stabilized on amorphous silica even in the case of a very low degree of hydration.

As a conclusion to this section, we have shown that GIPAW calculations are a safe basis for the validation of models related to silica/DPPC interfaces. On one hand, calculated ${ }^{1} \mathrm{H}$ chemical shifts discriminate between strongly and weakly $\mathrm{H}$-bonded $\mathrm{OH} /$ water moieties. However, ${ }^{31} \mathrm{P}$ GIPAW chemical shifts are most sensitive to the presence of water molecules, in strong interaction with the silica surface and the phosphate groups (configurations III and IV). All in all, GIPAW calculations validate realistic DFT models in the case of liposils.

Local Dynamics as Revealed by ${ }^{31} \mathrm{P}$ NMR Spectroscopy. Usually two main physical states are known for phospholipids: the fully hydrated state in which the lipids adopt a bilayer organization stabilized by water molecules and the dry state in which low water content prevents the bilayer organization on a large scale. The ${ }^{31} \mathrm{P}$ CSA parameters are well-known to be characteristic of these different states. Whereas the dry state gives rise to three distinct CSA principal components with $\Delta_{\mathrm{CS}} \sim-100 \mathrm{ppm},{ }^{73}$ the hydrated state gives rise to an axial CSA tensor $\Delta_{\mathrm{CS}} \sim 40 \mathrm{ppm}$
Table 3. GIPAW Calculated ${ }^{31} \mathrm{P}$ CSA Parameters (at $0 \mathrm{~K}$ ) for Modelled Configurations I to IV and Calculated Averaged CSA Values Considering a Rotation of the DPPC Head Group along an Axis Perpendicular to the Silica Surface and Considering a Two-Sites Jump with a Flip Angle $\varphi=90^{\circ}$ (See Text for Details and Figure 7) ${ }^{a}$

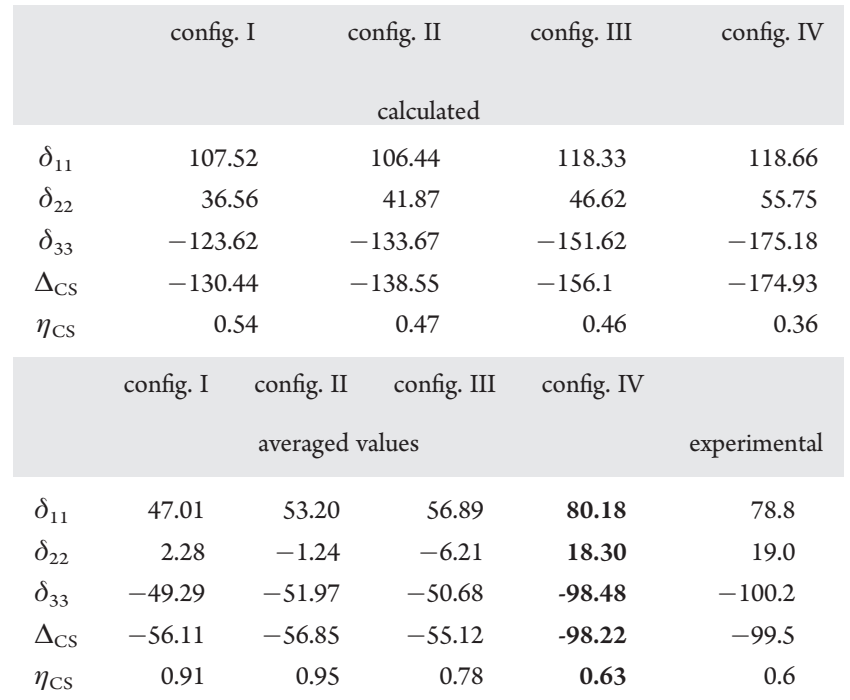

${ }^{a}$ In bold: averaged CSA parameters for configuration IV.

(depending on the temperature above or below the Tc). ${ }^{59} \mathrm{DPPC}$ in liposils is not belonging to any of these two categories but is closer to a SLB (where the substrate is the spherical amorphous silica shell on which the DPPC bilayer is adsorbed).

It is well-known that the CSA parameters $\left(\Delta_{\mathrm{CS}}\right.$ and $\left.\eta_{\mathrm{CS}}\right)$ are directly related to the motional behavior of phospholipids. For instance, the relatively small $\Delta_{\mathrm{CS}}$ value found for DPPC aqueous liposomes is due to their high mobility and has two main origins: (i) the reorientation of the liposome in water and (ii) the rotation of the phospholipid along the normal of the bilayer. Moreover, the latter phenomenon gives rise to an axial symmetry of the tensor that is verified experimentally since $\eta_{\mathrm{CS}} \approx 0$ is found (Figure 2 and Table 1). For dry DPPC, the $\Delta_{\mathrm{CS}}$ value is of course larger and the CSA tensor is found to be non symmetrical as the fast axial rotation is prevented (Figures 2). ${ }^{73}$ In the case of liposils, as soon as $T>298 \mathrm{~K}$, DPPC in site 2 (i.e., lipids in the inner layer) we observe $\eta_{\mathrm{CS}}$ close to 0 meaning that the fast axial rotation of the lipids is occurring. For DPPC in site 1 (i.e., lipids in the outer layer) we observe $\eta_{\mathrm{CS}}=0.5-0.6$ meaning that the lipid rotation perpendicularly to the bilayer is significantly reduced compared to the NMR time scale. In order to further validate the VASP models (and in particular the configuration IV in Figure 7), ${ }^{31}$ P CSA GIPAW parameters were carefully analyzed (Table 3 ). 
The experimental $\Delta_{\mathrm{CS}}$ for DPPC in site 1 is $-99.5 \mathrm{ppm}$ (considering RT CP MAS experiments from Figure 2 for $S / N$ reasons). The GIPAW calculated $\left|\Delta_{\mathrm{CS}}\right|$ for configurations I to IV are obviously overestimated $\left(\left|\Delta_{\mathrm{CS}}\right|>130 \mathrm{ppm}\right)$. In particular, the GIPAW values obtained for the configuration IV $\left(\Delta_{\mathrm{CS}}=\right.$ $-174.93 \mathrm{ppm}$ and $\left.\eta_{\mathrm{CS}}=0.36\right)$ are not in agreement with the experimental ones (Figures $2 \mathrm{f}$ and $2 \mathrm{~h}$ ). At first sight, it seems in contradiction with the established validity of the configuration IV in the previous sections $\left({ }^{1} \mathrm{H}\right.$ and ${ }^{31} \mathrm{P}$ isotropic chemical shifts). Thus, it seems reasonable to take into account a partial averaging of the CSA parameters through local dynamics. At this stage, it has to be emphasized that all GIPAW calculations were performed at $0 \mathrm{~K}$, neglecting all local motions (and therefore potential CSA averaging). Recently, it has been demonstrated that GIPAW calculations could be nicely reconciled with experimental data ${ }^{44}$ by: (i) considering fast rotation of chemical groups around particular axes and (ii) recalculating the corresponding averaged CSA values. Usually, the reorientation axes can be safely guessed from crystallographic data. The recalculation of the averaged CSA tensors is performed by orienting the rotation axes in the corresponding CSA Principal Axes Systems (PAS). The involved Euler angles are directly obtained from the GIPAW output.

In the case of the configuration IV, a rotation of the headgroup along an axis perpendicular to the silica surface (or more precisely, along the aliphatic chain direction) is first considered (see Figure 8, the dashed line corresponds to the axis of rotation; the direction of the long aliphatic chain is also presented). This particular choice of axis direction sounds as a reasonable choice, as it corresponds in principle to the rotation of the phospholipids along the normal of the bilayer in liposomes. The averaged CSA data were subsequently calculated by using the NMR weblab software developed by Macho, Brombacher and Spiess ${ }^{74}$ and the cone model. The cone angle $\theta$ and the $\alpha_{0}$ angle orient the axis of rotation and the CSA PAS obtained from GIPAW $\left(\theta=130.7^{\circ}\right.$, $\alpha_{0}=66.8^{\circ}$ for the configuration IV - the angles for the other configurations can be obtained upon request to the authors). As $\eta_{\text {CS }} \neq 0$ for site 1 in liposils (Table 1 ), a fast continuous rotation can be excluded (as well as three $120^{\circ}$ sites jump models with equal probabilities). As a consequence, a simple two sites jump model, characterized by the flip angle $\varphi$ (Figure 8 ) has been first considered (with equal probabilities and under fast motional limit). Under these assumptions, the best agreement between calculated and experimental data is obtained for $\varphi \approx 90^{\circ}$ (Table 3 and Figure $2 \mathrm{~g}$ ). For $\varphi=90^{\circ},\left(\eta_{\mathrm{CS}}\right)_{\text {calc. }}=0.63$ and $\left(\Delta_{\mathrm{CS}}\right)_{\text {calc. }}=-98.22 \mathrm{ppm}$ (to be compared to 0.6 and $-99.5 \mathrm{ppm}$, respectively). At this stage, several comments have to be made: (i) GIPAW calculations at $0 \mathrm{~K}$ can be reconciled with experimental data at room temperature by taking into account a reasonable model of molecular reorientation. It does not mean that the two sites jump model with $\varphi=90^{\circ}$ is the unique answer. More complex reorientation schemes could probably lead to the same averaging of the CSA tensors. Nevertheless, our data support the quenching of the fast free rotation of the lipids corresponding to site 1 that is is induced by the silica shell that covers DPPC's liposomes and might be due to the strong $\mathrm{H}$-bond interaction via water molecules between the silica and the DPPC headgroup. Thus, such kind of molecular motion based on jumps model (with a restricted angle) is coherent with the dynamic of DPPC existing in the outer layer of liposil. Low temperature static experiment could be an option to confirm these assumptions. However, below $0{ }^{\circ} \mathrm{C}$, the degradation of liposils was observed. We want to stress here that the described reorientation scheme for DPPC is still an assumption at this stage. Nevertheless, it seems interesting to introduce local dynamics in GIPAW calculations for future works based on the VASP/solid state NMR/GIPAW approach.

(ii) On the basis of ${ }^{31} \mathrm{P}$ isotropic chemical shifts, configuration III (involving two $\mathrm{H}$ bonds between the phosphate group and two water molecules) could be considered as a realistic model for the silica/liposome interface. The averaged CSA values are also presented in Table 3 (for a two sites jump model with $\left.\varphi=90^{\circ}\right)$. The averaged $\eta_{\mathrm{CS}}(=0.78)$ is comparable to the experimental value, whereas $\left|\Delta_{C S}\right|$ is underestimated. The discrepancy between the experimental and averaged data could be related to the presence of two $\mathrm{H}$-bonds in the case of configuration III (with $\mathrm{H} 5$ and H6). These two H-bonds could probably hinder the two sites jump reorientation. In other words, the simple reorientation scheme applied to configuration IV cannot be easily extended to configuration III. We did not try to further investigate potential reorientation models for configuration III.

At the end of this section, it must be mentioned that deuterium NMR could be used as a complementary technique for the detailed characterization of local dynamics. ${ }^{2} \mathrm{H}$ NMR has been often used in the past for the study of the dynamic of lipid bilayers as the lipids can be labeled at specific positions. ${ }^{75}$ Deuterated water can be also used in the syntheses and the dynamic properties of water in lipid/water dispersions have also been studied through ${ }^{2} \mathrm{H}$ NMR. ${ }^{76}$ Moreover, the "dilution" of protons should lead to an increase in ${ }^{1} \mathrm{H}$ MAS resolution, ${ }^{77}$ circumventing in a sense the problem of slow MAS spinning (see above). All these new directions will be considered in a near future.

\section{CONCLUSIONS}

In this work, it has been demonstrated that the combination of VASP/solid state NMR/GIPAW represents a major breakthrough 
for the detailed characterization of organic-inorganic interfaces. Whereas DFT modeling and solid state NMR experiments are usually considered independently, the GIPAW calculations of NMR parameters establish a link between theoretical models and experimental data. Most importantly, both calculated and experimental values allowed validation of specific configurations of the DPPC moieties adsorbed on an amorphous silica slab.

We proved the ability of $\left\{{ }^{1} \mathrm{H}-{ }^{29} \mathrm{Si}\right\}{ }^{1} \mathrm{H}$ and $\left\{{ }^{1} \mathrm{H}-{ }^{31} \mathrm{P}\right\}{ }^{1} \mathrm{H}$ Double CP experiments to bring precise information concerning the proximity between the silica shell and the phospholipids. For further increase in resolution, such an approach could be combined with ${ }^{1} \mathrm{H}$ homonuclear decoupling techniques and/or ${ }^{1} \mathrm{H}$ double quantum MAS experiments. We demonstrated through molecular dynamics and geometry optimization that the stabilization of a PC moiety onto hydroxylated silica is done through the phosphate group and not through the choline group, in accordance with the NMR results. First principles calculations of ${ }^{1} \mathrm{H}$ and ${ }^{31} \mathrm{P}$ chemical shifts (corresponding to energetically favorable configurations) evidenced that a direct interaction between phosphates and silanols is not occurring in liposils. Thus, we emphasize the role of interfacial water which is acting as a relay in the H-bond network that further stabilizes the hybrid interface. Finally, a model for the molecular motion of DPPC in liposils is proposed thanks to the detailed study of the ${ }^{31} \mathrm{P}$ CSA tensorial parameters. Indeed, the overestimated calculated data are averaged using a molecular motion model. Thus, considering the partial reorientation of DPPC through two discrete jumps around the normal axis to the silica, the averaged CSA values fit well with experimental data. Obviously, the VASP/solid state NMR/GIPAW combined approach can be safely extended to a large number of organic-inorganic interfaces.

\section{ASSOCIATED CONTENT}

S Supporting Information. Figures S1-S11, including NMR pulse sequences, SEM images, ${ }^{1} \mathrm{H}$ and ${ }^{31} \mathrm{P}$ NMR spectra, NMR simulations, VT experiments, and ${ }^{1} \mathrm{H}-{ }^{1} \mathrm{H}$ COSY. This material is available free of charge via the Internet at http://pubs. acs.org.

\section{AUTHOR INFORMATION}

\section{Corresponding Author}

thierry.azais@upmc.fr

\section{Present Addresses}

${ }^{\#}$ Sciences Chimiques de Rennes-UMR CNRS 6226, Campus de Beaulieu, 263 av. Général Leclerc, 35042 Rennes Cedex, France.

${ }^{\nabla}$ Nano and Computational Materials Lab, Catalysis Division, National Chemical Laboratory CSIR, Dr. Homi Bhabha Road, Pashan, Pune -411 008, India.

\section{Author Contributions}

${ }^{\triangle}$ These authors contributed equally to this work.

\section{ACKNOWLEDGMENT}

Financial support from the Young Researcher ANR Grant NanoBioMat No. ANR-06-JCJC-0089 (TA and CR) and the Blanc ANR Grant No. ANR-05-BLAN-0255 (T.A. and L.D.) are highly acknowledged. This work was performed using HPC resources from GENCI- [CCRT/CINES/IDRIS] (Grant 2010-[x2010082022]) and the CCRE of Universite Pierre et Marie Curie. N.F. benefited from a Ph.D. grant from the CNano program of the Ile-de-France region. Dr. Dominique Massiot, director of CEMHTI, and Dr. Franck Fayon are greatly acknowledged for giving us the opportunity to record experiments on the NMR spectrometers located in their laboratory. We thank Dr. François Ribot (LCMCP) for help to record solution NMR spectra and Patrick Le Griel (LCMCP) for the TEM observations.

\section{REFERENCES}

(1) Langer, R. Nature 1998, 392, 5-10.

(2) Vallet-Regi, M.; Balas, F.; Arcos, D. Angew. Chem. 2007, 46, $7548-7558$

(3) Sulkowski, W. W.; Pentak, D.; Nowak, K.; Sulkowska, A. J. Mol. Struct. 2005, 744, 737-747.

(4) Mohanraj, V. J.; Barnes, T. J.; Prestidge, C. A. Int. J. Pharm. 2010, 392, 285-293, and references therein..

(5) Ciobanu, M.; Heurtault, B.; Schulz, P.; Ruhlmann, C.; Muller, C. D.; Frisch, B. Int. J. Pharm. 2007, 344, 154-157.

(6) (a) Liu, J.; Stace-Naughton, A.; Jiang, X.; Brinker, C. J. J. Am. Chem. Soc. 2009, 131, 1354-1355. (b) Ashley, C. E.; Carnes, E. C.; Phillips, G. K.; Padilla, D.; Durfee, P. N.; Brown, P. A.; Hanna, T. N.; Liu, J.; Phillips, B.; Carter, M. B.; Carroll, N. J.; Jiang, X.; Dunphy, D. R.; Willman, C. L.; Petsev, D. N.; Evans, D. G.; Parikh, A. N.; Chackerian, B.; Wharton, W.; Peabody, D. S.; Brinker, C. J. Nat. Mater. 2011, 10, 389-397.

(7) Barbé, C.; Bartlett, J.; Kong, L.; Finnie, K.; Lin, H. Q.; Larkin, M.; Calleja, S.; Bush, A.; Calleja, G. Adv. Mater. 2004, 16, 1959-1966.

(8) Liu, J.; Jiang, X.; Ashley, C.; Brinker, C. J. J. Am. Chem. Soc. 2009, $131,7567-7569$.

(9) Bégu, S.; Durand, R.; Lerner, D. A.; Charnay, C.; Tourné-Péteilh, C.; Devoisselle, J. M. Chem. Commun. 2003, 640.

(10) Bégu, S.; Girod, S.; Lerner, D. A.; Jardiller, N.; Tourné-Péteilh, C.; Devoisselle, J.-M. J. Mater. Chem. 2004, 14, 1316.

(11) Bégu, S.; Aubert Pouëssel, A.; Lerner, D. A.; Tourné-Péteilh, C.; Devoisselle, J.-M. J. Controlled Release 2007, 118, 1.

(12) Steinberg, Y.; Schroeder, A.; Talmon, Y.; Schmidt, J.; Khalfin, R. L.; Cohen, Y.; Devoisselle, J.-M.; Begu, S.; Avnir, D. Langmuir 2007, 23, 12024-12031.

(13) Corma, A.; Diaz, U.; Arricada, M.; Fernandez, E.; Ortega, I. Angew. Chem. 2009, 48, 6247-6250.

(14) Yaroslavov, A. A.; Sybachin, A. V.; Schrinner, M.; Ballauff, M.; Tsarkova, L.; Kesselman, E.; Schmidt, J.; Talmon, Y.; Menger, F. M. J. Am. Chem. Soc. 2010, 132, 5948-5949.

(15) Li, Y.; Yip, W. T. J. Am. Chem. Soc. 2005, 127, 12756-12757.

(16) Mueller, P.; Rudin, D. O.; Tien, H. T.; Wescott, W. C. Nature 1962, 194, 979-980.

(17) Cornell, B. A.; BraachMaksvytis, V. L. B.; King, L. G.; Osman, P. D. J.; Raguse, B.; Wieczorek, L.; Pace, R. J. Nature 1997, 387, 580-583.

(18) Viitala, T.; Hautala, J. T.; Vuorinen, J.; Wiedmer, S. K. Langmuir 2007, 23, 609-618.

(19) Wang, Z.; Yang, S. Langmuir 2008, 24, 11616-11624.

(20) Nash, T.; Allison, A. C.; Harrington, J. S. Nature 1966, 210, 259.

(21) Ugliengo, P.; Sodupe, M.; Musso, F.; Bush, I. J.; Orlando, R.; Dovesi, R. Adv. Mater. 2008, 20, 4579-4583.

(22) Leung, K.; Nielsen, I. M. B.; Criscenti, L. J. J. Am. Chem. Soc. 2009, 131, 18358-18365.

(23) Peng, L.; Qisui, W.; Xi, L.; Chaocan, Z. Colloids Surf., A 2009, $334,112-115$

(24) Xu, M.; Harris, K. D. M.; Thomas, J. M. J. Am. Chem. Soc. 2008, 130, 5880-5882.

(25) Kresse, G.; Hafner, J. Phys. Rev. B 1994, 49, 14251.

(26) Bonhomme, C.; Coelho, C.; Baccile, N.; Gervais, C.; Azaïs, T.; Babonneau, F. Acc. Chem. Res. 2007, 40, 738-746.

(27) Pickard, C. J.; Mauri, F. Phys. Rev. B 2001, 63, 245101. 
(28) Tanev, P. T.; Pinnavaia, T. J. Supramol. Sci. 1998, 5, 399-404.

(29) Fowler, C. E.; Khushalani, D.; Mann, S. J. Mater. Chem. 2001, 11, 1968-1971.

(30) Hubert, D.; Jung, M.; Frederik, P.; Bomans, P.; Meuldijk, J.; German, A. Adv. Mater. 2000, 12, 17.

(31) Beck, J. S.; Vartuli, J. C.; Roth, W. J.; Leonowicz, M. E.; Kresge, C. T.; Schmitt, K. D.; Chu, C. T. D.; Olson, D. H.; Sheppard, E. W.; McCullen, S. B.; Higgins, J. B.; Schlenker, J. L. J. Am. Chem. Soc. 1992, 114, 10834-10843.

(32) Tielens, F.; Gervais, C.; Lambert, J.-F.; Mauri, F.; Costa, D. Chem. Mater. 2008, 20, 3336.

(33) Costa, D.; Tougerti, A.; Tielens, F.; Gervais, C.; Stievano, L.; Lambert, J.-F. Phys. Chem. Chem. Phys. 2008, 42, 6360-6368.

(34) Pines, A.; Gibby, M. G.; Waugh, J. S. J. Chem. Phys. 1973, 59, 569-590.

(35) Epping, J. D.; Chmelka, B. F. Curr. Opin. Colloid Interface Sci. 2006, 11, 81-117.

(36) Baccile, N.; Laurent, G.; Bonhomme, C.; Innocenzi, P.; Babonneau, F. Chem. Mater. 2007, 19, 1343.

(37) Wiench, J. W.; Bronnimann, C. E.; Lin, V. S-Y.; Pruski, M. J. Am. Chem. Soc. 2007, 129, 12076-12077.

(38) Mao, K.; Kobayashi, T.; Wiench, J. W.; Chen, H.-T.; Tsai, C.H.; Lin, V. S.-Y.; Pruski, M. J. Am. Chem. Soc. 2010, 132, 12452-12457.

(39) (a) Webber, A. L.; Emsley, L.; Claramunt, R. M.; Brown, S. P. J. Phys. Chem. A 2010, 114, 10435-10442. (b) Carnevale, D; del Amo, V.; Philip, D.; Ashbrook, S. E. Tetrahedron 2010, 66, 6238-6250. (c) Stievano, L.; Tielens, F.; Lopes, I.; Folliet, N.; Gervais, C.; Costa, D.; Lambert, J. F. Cryst. Growth Design 2010, 10, 3657-3668. (d) Webber, A. L.; Elena, B.; Griffin, J. M.; Yates, J. R.; Pham, T. N.; Mauri, F.; Pickard, C. J.; Gil, A. M.; Stein, R.; Lesage, A.; Emsley, L.; Brown, S. P. Phys. Chem. Chem. Phys. 2010, 12, 6970-6983.

(40) (a) Widdifield, C. M.; Bryce, D. L. J. Phys. Chem. A 2010 114, 10810-10823. (b) Hamaed, H.; Ye, E.; Udachin, K.; Schurko, R. W. J. Phys. Chem. B 2010, 114, 6014-6022. (c) Middlemiss, D. S.; Blanc, F.; Pickard, C. J.; Grey, C. P. J. Magn. Reson. 2010, 204, 1-10. (d) Truflandier, L. A.; Boucher, F.; Payen, C.; Hajjar, R.; Millot, Y.; Bonhomme, C.; Steunou, N. J. Am. Chem. Soc. 2010, 132, 4653-4668. (e) Hanna, J. V.; Pike, K. J.; Charpentier, T.; Kemp, T. F.; Smith, M. E.; Lucier, B. E. G.; Schurko, R. W.; Cahill, L. S. Chem.-Eur. J. 2010, 16, 3222-3239. (f) Laurencin, D.; Gervais, C.; Wong, A.; Coelho, C.; Mauri, F.; Massiot, D.; Smith, M. E.; Bonhomme, C. J. Am. Chem. Soc. 2009, 131, 13430-13440. (g) Johnston, K. E.; Tang, C. C.; Parker, J. E.; Knight, K. S.; Lightfoot, P.; Ashbrook, S. E. J. Am. Chem. Soc. 2010, 132, 8732-8746. (h) Byrne, P. J.; Warren, J. E.; Morris, R. E.; Ashbrook, S. E. Solid State Sci. 2009, 11, 1001-1006. (i) Pourpoint, F.; Kolassiba, A.; Gervais, C.; Azaïs, T.; Bonhomme-Coury, L.; Bonhomme, C.; Mauri, F. Chem. Mater. 2007, 19, 6367-6369.

(41) Reader, S. W.; Mitchell, M. R.; Johnston, K. E.; Pickard, C. J.; Whittle, K. R.; Ashbrook, S. E. J. Phys. Chem. C 2009, 113, 18874-18883.

(42) (a) Pedone, A.; Charpentier, T.; Menziani, M. C. Phys. Chem. Chem. Phys. 2010, 12, 6054-6066. (b) Ispas, S.; Chapentier, T.; Mauri, F.; Neuville, D. R. Solid State Sci. 2010, 12, 182-192. (c) Kibalchenko, M.; Yates, J. R.; Massobrio, C.; Pasquarello, A. Phys. Rev. B 2010, 82,020202

(43) Chappell, H.; Duer, M.; Groom, N.; Pickard, C.; Bristowe, P. Phys. Chem. Chem. Phys. 2008, 10, 600-606.

(44) (a) Gervais, C.; Bonhomme-Coury, L.; Mauri, F.; Babonneau, F.; Bonhomme, C. Phys. Chem. Chem. Phys. 2009, 11, 6953-6961. (b) Gervais, C.; Coelho, C.; Azais, T.; Maquet, J.; Laurent, G.; Pourpoint, F.; Bonhomme, C.; Florian, P.; Alonso, B.; Guererro, G.; Mutin, P. H.; Mauri, F. J. Magn. Reson. 2007, 187, 131-140. (c) Griffin, J. M.; Wimperis, S.; Berry, A. J.; Pickard, C. J.; Ashbrook, S. E. J. Phys. Chem. C 2009, 113, 465-471. (d) De Gortari, I.; Portella, G.; Salvatella, X.; Bajaj, V. S.; van der Wel, P. C. A.; Yates, J. R.; Segall, M. D.; Pickard, C. J.; Payne, M. C.; Vendruscolo, M. J. Am. Chem. Soc. 2010, 132, 5993-6000. (e) Griffin, J. M.; Miller, A. J.; Berry, A. J.; Wimperis, S.; Ashbrook, S. E. Phys. Chem. Chem. Phys. 2010, 12, 2989-2998.

(45) Bangham, A. D. J. Mol. Biol. 1965, 13, 238.
(46) Nielsen, C.; Bildsøe, H.; Jakobsen, H. J.; Levitt, M. H. J. Chem. Phys. 1994, 101, 1805-1812.

(47) Yannoni, C. S. Acc. Chem. Res. 1982, 15, 201-208.

(48) Massiot, D.; Fayon, F.; Capron, M.; King, I.; Le Calvé, S.; Alonso, B.; Durand, J.-O.; Bujoli, B.; Gan, Z.; Hoaston, G. Magn. Reson. Chem. 2002, 40, 70

(49) Perdew, J. P.; Wang, Y. Phys. Rev. B 1992, 45, 13244.

(50) (a) Perdew, J. P.; Burke, K.; Ernzerhof, M. Phys. Rev. Lett. 1996, 77, 3865. (b) Zhang, Y. K.; Yang, W. T. Phys. Rev. Lett. 1998, 80, 890.

(51) Monkhorst, H. J.; Pack, J. D. Phys. Rev. B 1976, 13, 5188.

(52) Blöchl, P. E.; Jepsen, O.; Andersen, O. K. Phys. Rev. B 1994, 49, 16223.

(53) Mauri, F.; Cote, M.; Yoon, Y.; Pickard, C.; Heynes, P. PARATEC (PARAllel Total Energy Code); Pfrommer, B., Raczkowski, D., Canning, A., Louie, S. G., Eds.; www.nersc.gov/projects/paratec.

(54) Perdew, J. P.; Burke, K.; Ernzerhof, M. Phys. Rev. Lett. 1997, 78, 1396.

(55) Troullier, N.; Martins, J. L. Phys. Rev. B 1991, 43, 1993.

(56) Kleinman, L.; Bylander, D. Phys. Rev. Lett. 1982, 48, 1425.

(57) Gervais, C.; Profeta, M.; Lafond, V.; Bonhomme, C.; Azaiis, T.; Mutin, H.; Pickard, C. J.; Mauri, F.; Babonneau, F. Magn. Reson. Chem. 2004, 42, 445 .

(58) Gervais, C.; Dupree, R.; Pike, K.; Bonhomme, C.; Profeta, M.; Pickard, C. J.; Mauri, F. J. Phys. Chem. A 2005, 109, 6960.

(59) Dufourc, E. J.; Mayer, C.; Stohrer, J.; Althoff, G.; Kothe, G. Biophys. J. 1992, 61, 42-57.

(60) Hertzfeld, J.; Berger, A. E. J. Chem. Phys. 1980, 73, 6021.

(61) Traikkia, M.; Warschawski, D. E.; Recouvreur, M.; Cartaud, J.; Devaux, P. F. Eur. Biophys. J. 2000, 29, 184.

(62) Forbes, J.; Bower, J.; Shan, X.; Moran, L.; Oldfield, E. J. Chem. Soc.-Faraday Trans. I 1988, 84, 3821-3849.

(63) (a) Ishii, Y.; Tycko, R. J. Magn. Reson. 2000, 142, 199-204. (b) Ishii, Y.; Yesinovski, J. P.; Tycko, R. J. Am. Chem. Soc. 2001, 123, 2921-2922. (c) Paulson, E. K.; Morcombe, C. R.; Gaponenko, V.; Dancheck, B.; Byrd, R. A.; Zilm, K. W. J. Am. Chem. Soc. 2003, $125,15831-15836$

(64) Liu, C. C.; Maciel, G. E. J. Am. Chem. Soc. 1996, 118, 5103-5119.

(65) Pourpoint, F.; Gervais, C.; Bonhomme-Coury, L.; Azaïs, T.; Coelho, C.; Mauri, F.; Alonso, B.; Babonneau, F.; Bonhomme, C. Appl. Magn. Reson. 2007, 32, 435-457.

(66) Krishnamurty, S.; Stefanov, M.; Mineva, T.; Bégu, S.; Devoisselle, J. M.; Goursot, A.; Zhu, R; Salahub, D. R. J. Phys. Chem. B 2008, 112, 13433-13442.

(67) Snyder, J. A.; Madura, J. D. J. Phys. Chem. B 2008, 112 (23), 7095-7103.

(68) Salager, E.; Day, G. M.; Stein, R. S.; Pickard, C. J.; Elena, B.; Emsley, L. J. Am. Chem. Soc. 2010, 132, 2564.

(69) Bonhomme, C.; Gervais, C.; Coelho, C.; Pourpoint, F.; Azais, T.; Bonhomme-Coury, L.; Babonneau, F.; Jacob, G.; Ferrari, M.; Canet, D.; Yates, J. R.; Pickard, C. J.; Joyce, S. A.; Mauri, F.; Massiot, D. Magn. Reson. Chem. 2010, 48, S86-102.

(70) Doshi, D. A.; Dattelbaum, A. M.; Watkins, E. B.; Brinker, C. J.; Swanson, B. I.; Shreve, A. P.; Parikh, A. N.; Majewski, J. Langmuir 2005, $21,2865-2870$

(71) Roark, M.; Feller, S. E. Langmuir 2008, 24, 12469-12473.

(72) Zwang, T. J.; Fletcher, W. R.; Lane, T. J.; Johal, M. S. Langmuir 2010, 26, 4598-4601.

(73) Kohler, S. J.; Klein, M. P. Biochemistry 1976, 15, 967-973.

(74) Macho, V.; Brombacher, L.; Spiess, H. W. Appl. Magn. Reson. 2001, 20, 405; see: http://weblab.mpimainz.mpg.de/weblab/weblab. html

(75) (a) Ulrich, A. S.; Watts, A. Biophys. J. 1994, 66, 1441-1449. (b) Watts, A. Biochim. Biophys. Acta 1998, 1376, 297-318.

(76) Volke, F.; Eisenblätter, S.; Galle, J.; Klose, G. Chem. Phys. Lipids 1994, 2, 121-131.

(77) Chevelkov, V.; Rehbein, K.; Diehl, A.; Reif, B. Angew. Chem. Int. Ed. 2006, 45, 3878-3881. 



Figure 1. (a) TEM observation of liposils and (b) schematic representation of a liposil entity.
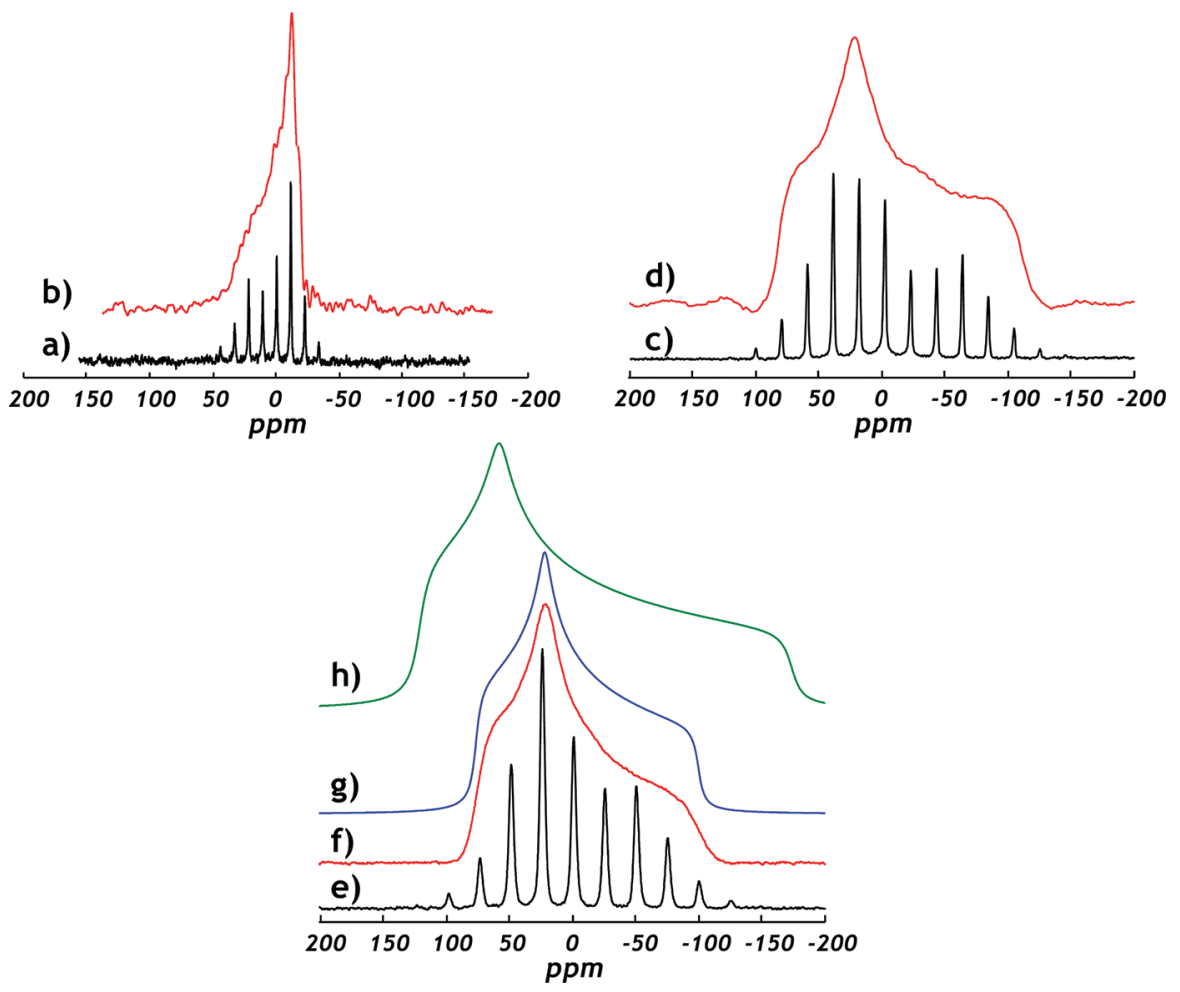

Figure 2. ${ }^{31} \mathrm{P}$ proton-decoupled (a) slow MAS $\left(v_{\mathrm{MAS}}=1.88 \mathrm{kHz}\right)$ and $(\mathrm{b})$ static echo spectrum of DPPC aqueous liposomes; $(\mathrm{c})$ slow MAS $\left(v_{\mathrm{MAS}}=2.5\right.$ $\mathrm{kHz})$ and $(\mathrm{d})$ static echo spectrum of dry DPPC; (e) slow CP MAS $\left(v_{\mathrm{MAS}}=3 \mathrm{kHz}\right)$ and $(\mathrm{f})$ static CP echo spectrum of liposils; (g) simulation with a pure CSA line shape $\left.\left(\Delta_{\mathrm{CS}}=-99.5 \mathrm{ppm}, \eta_{\mathrm{CS}}=0.6\right) ; \mathrm{h}\right)$ pure CSA line shape obtained by GIPAW calculations at $0 \mathrm{~K}$ corresponding to Configuration IV $\left(\Delta_{\mathrm{CS}}=-174.93 \mathrm{ppm}, \eta_{\mathrm{CS}}=0.36\right)$. See text. 

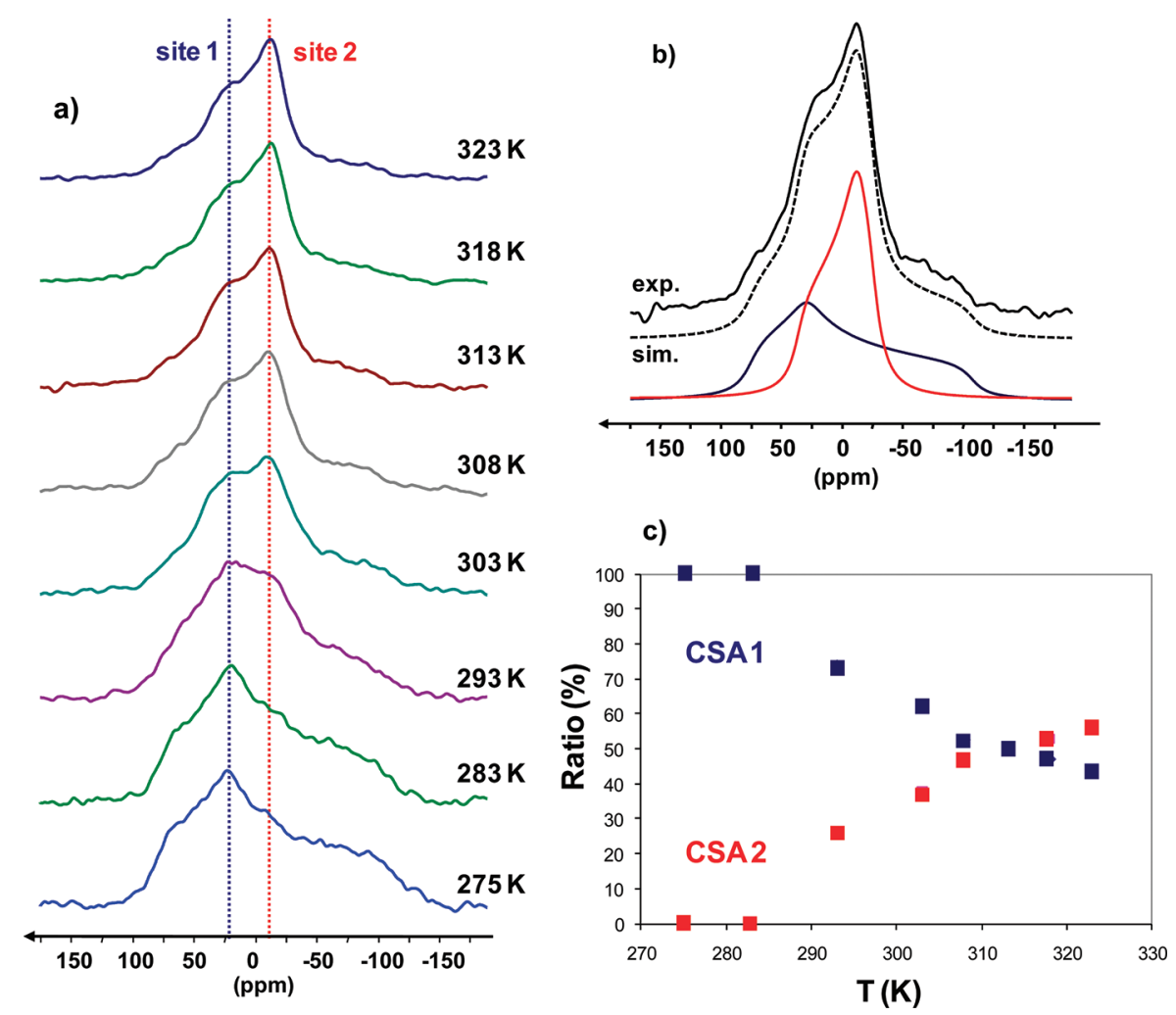

Figure 3. (a) variable temperature ${ }^{31} \mathrm{P}$ static echo spectra. (b) Example of simulation with two sites at $T=313 \mathrm{~K}\left(\mathrm{CSA} 1\right.$, blue: $\Delta_{\mathrm{CS}}=-105$ ppm, $\eta_{\mathrm{CS}}=$ 0.5 ; CSA 2 , red: $\Delta_{\mathrm{CS}}=35 \mathrm{ppm}, \eta_{\mathrm{CS}}=0.3-\delta_{\text {iso. }}\left({ }^{31} \mathrm{P}\right)=0.7 \mathrm{ppm}$ for sites 1 and 2 ). (c) quantification of the CSA tensors versus temperature (the CSA parameters obtained in (b) are fixed, only the intensities are used as variables).

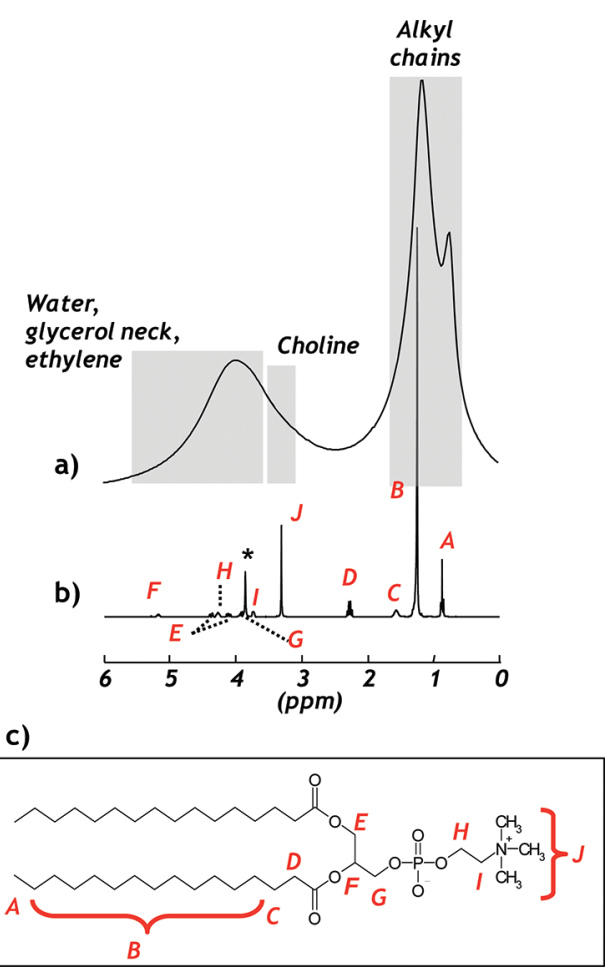

Figure 4. (a) Single pulse ${ }^{1} \mathrm{H}$ MAS $\left(v_{\text {MAS }}=5 \mathrm{kHz}\right)$ spectrum of liposils and assignment of the principal regions. (b) Assigned ${ }^{1} \mathrm{H}$ spectrum of DPPC in $\mathrm{CDCl}_{3}$ (see Figure $\mathrm{S} 9$ of the SI), (c) schematic representation of DPPC with atoms labeling. ${ }^{*}$ denotes residual water in $\mathrm{CDCl}_{3}$.



Figure 5. $\left\{{ }^{1} \mathrm{H}-{ }^{29} \mathrm{Si}\right\}{ }^{1} \mathrm{H}$ Double $\mathrm{CP}$ spectra of liposils. The first contact time $\left(t_{\mathrm{CP}} 1\right)$ was set to $3 \mathrm{~ms}$. The variable second contact time $\left(t_{\mathrm{CP}} 2\right)$ is indicated on each spectrum (see Figure S1 of the SI for the NMR sequence). 


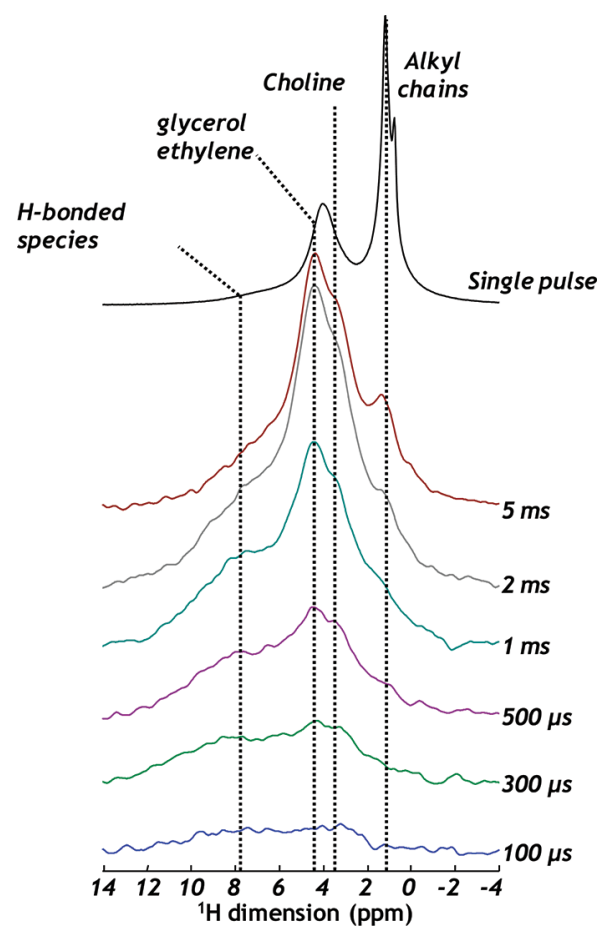

Figure 6. $\left\{{ }^{1} \mathrm{H}-{ }^{31} \mathrm{P}\right\}{ }^{1} \mathrm{H}$ Double $\mathrm{CP}$ spectra of liposils. The first contact time $\left(t_{\mathrm{CP}} 1\right)$ was set to $5 \mathrm{~ms}$. Variable second contact time $\left(t_{\mathrm{CP}} 2\right)$ is indicated on each spectrum (see Figure S1 of the SI for the NMR sequence).

(a) Config I

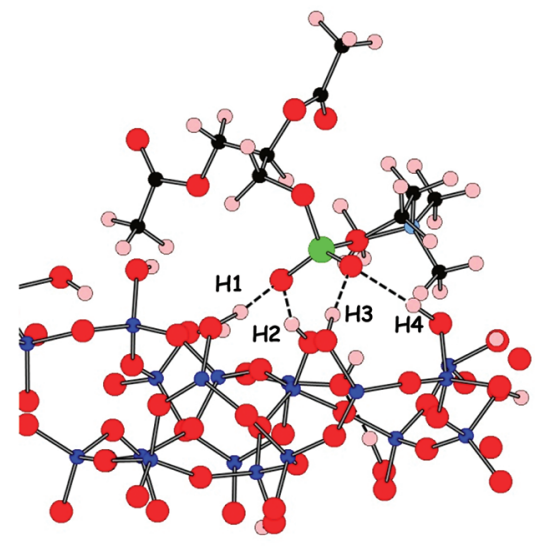

(b) Config II



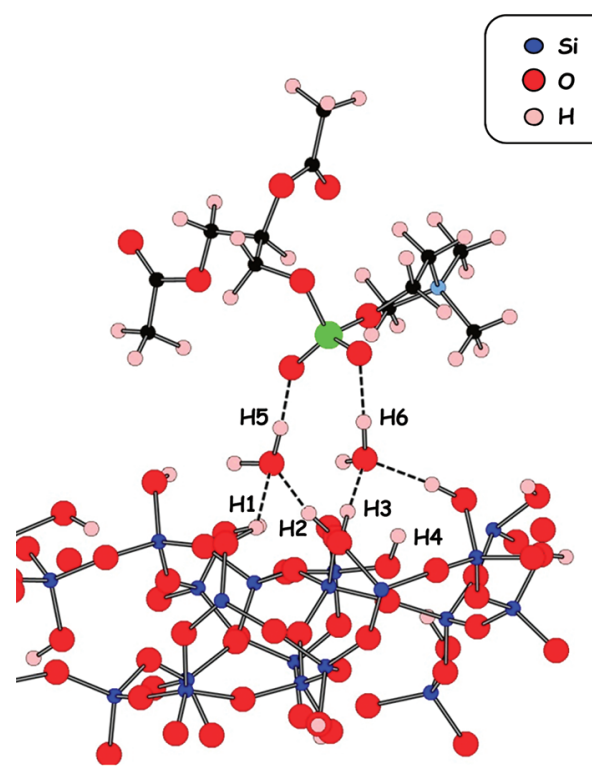

(c) Config III

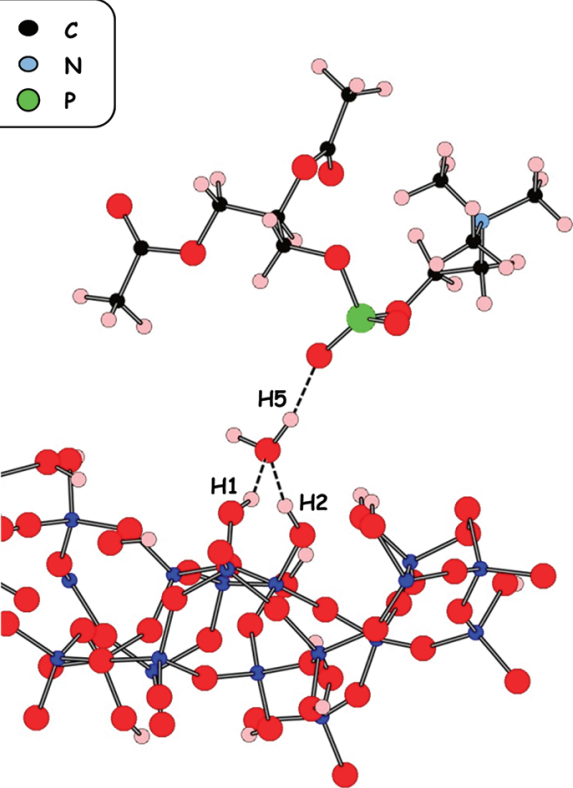

(d) Config IV

Figure 7. Representation of the configurations I, II, III, and IV obtained through geometry optimization (see the Experimental Section). 




\section{Config IV}

Figure 8. Representation of the rotation of the DPPC headgroup along a perpendicular axis to the silica surface (black dashed line: axis for the $90^{\circ}$ reorientation of the ${ }^{31} \mathrm{P}$ CSA tensor. Red dashed line: orientation of the chain of the DPPC molecule). 
Supporting Information

\section{Investigation of the Interface in Silica-Encapsulated Liposomes by Combining Solid State NMR and First Principles Calculations}

Nicolas Folliet, ${ }^{1,2 \dagger}$ Claire Roiland, ${ }^{1 \dagger}$ Sylvie Bégu, ${ }^{3}$ Anne Aubert, ${ }^{3}$ Tzonka Mineva, ${ }^{3}$ Annick Goursot, ${ }^{3}$ Kaliaperumal Selvaraj, ${ }^{3}$ Luminita Duma, ${ }^{4}$ Frederik Tielens, ${ }^{2}$ Francesco Mauri, ${ }^{5}$ Guillaume Laurent, ${ }^{1}$ Christian Bonhomme, ${ }^{1}$ Christel Gervais, ${ }^{1}$ Florence Babonneau ${ }^{1}$ and Thierry Azaiis ${ }^{1 *}$.

${ }^{1}$ UPMC Univ Paris 06 \& CNRS, UMR 7574, Chimie de la Matière Condensée de Paris, Collège de France, 11, place Marcelin Berthelot, F-75005, Paris, France

${ }^{2}$ UPMC Univ Paris 06 \& CNRS, UMR 7197, Laboratoire de Réactivité de Surface, 4, Place Jussieu, F-75005 Paris, France

${ }^{3}$ Institut Charles Gerhardt, UMR 5253 CNRS/ENSCM/UM1, Montpellier, France

${ }^{4}$ Ecole Normale Supérieure, 24 rue Lhomond, 75231 Paris Cedex 05, France

${ }^{5}$ UPMC Univ Paris 06 \& CNRS, UMR 7590, Institut de Minéralogie et Physique des Milieux Condensés, Campus Boucicaut, 75015 Paris, France

* To whom correspondence should be addressed: thierry.azais@upmc.fr

$\dagger$ Both authors contributed equally to this work 


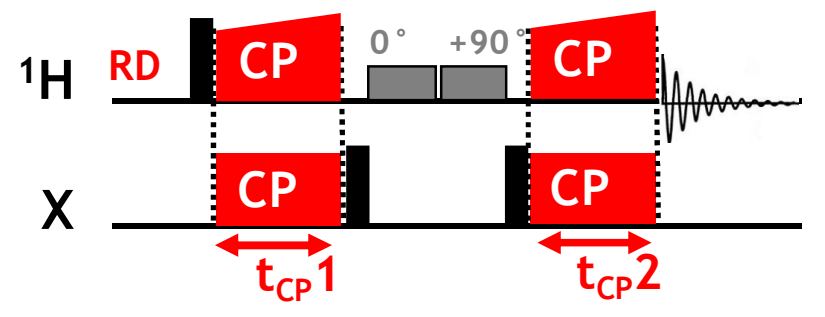

Figure S1: Schematic description of the ${ }^{1} H \rightarrow X \rightarrow{ }^{1} H$ Double CP experiment $\left(X={ }^{29}\right.$ Si or $\left.{ }^{31} P\right)$. 




Figure S2: Representative TEM picture of liposils after solid state NMR measurements 


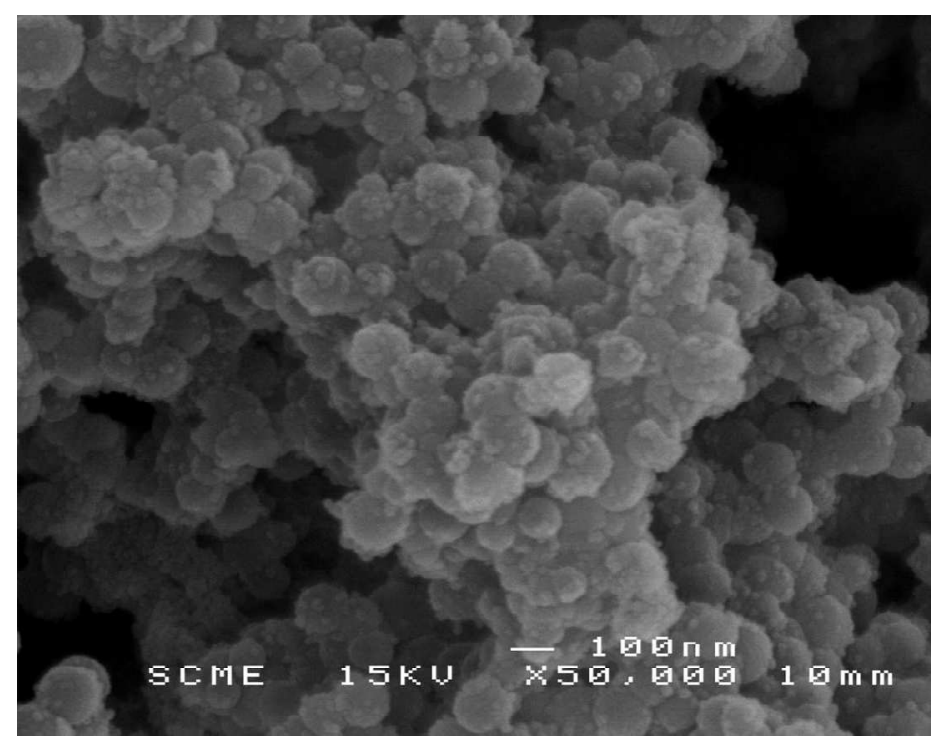

Figure S3: Representative SEM picture of liposils 

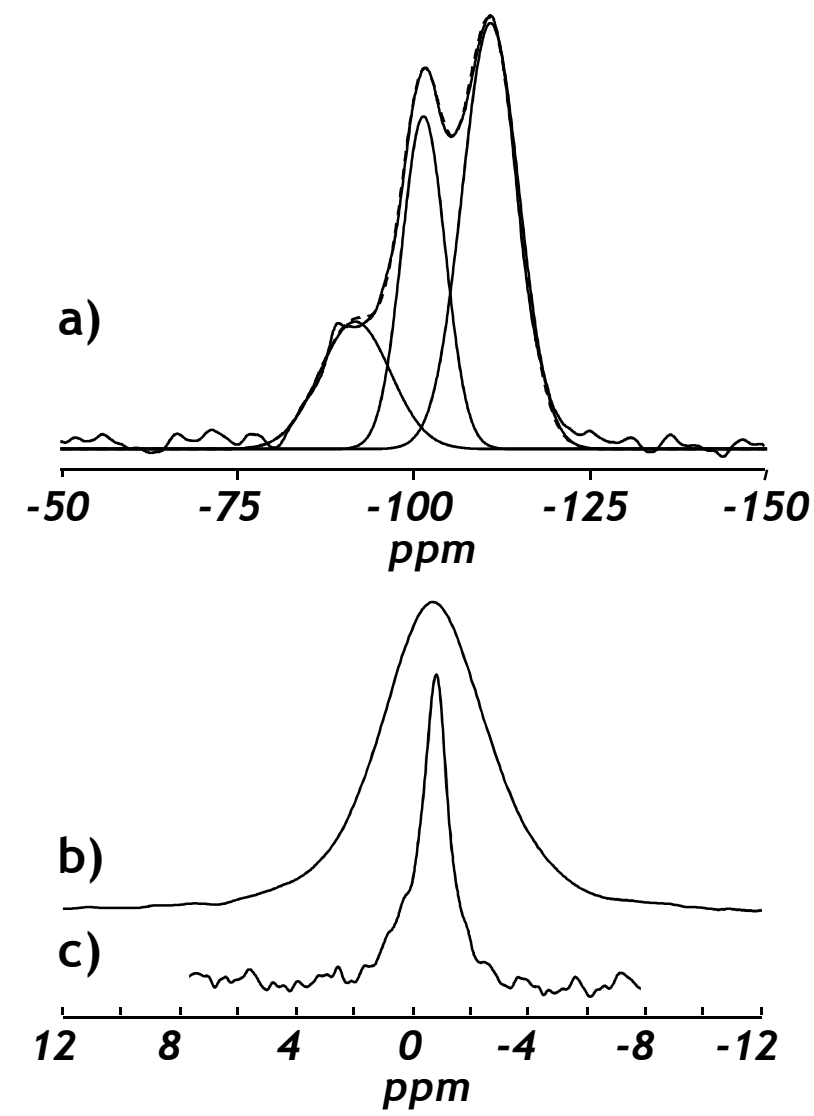

Figure S4: a) ${ }^{29}$ Si proton-decoupled MAS spectrum of liposils, b) ${ }^{31} \mathrm{P}$ proton-decoupled MAS spectrum of liposils and c) DPPC liposomes. 

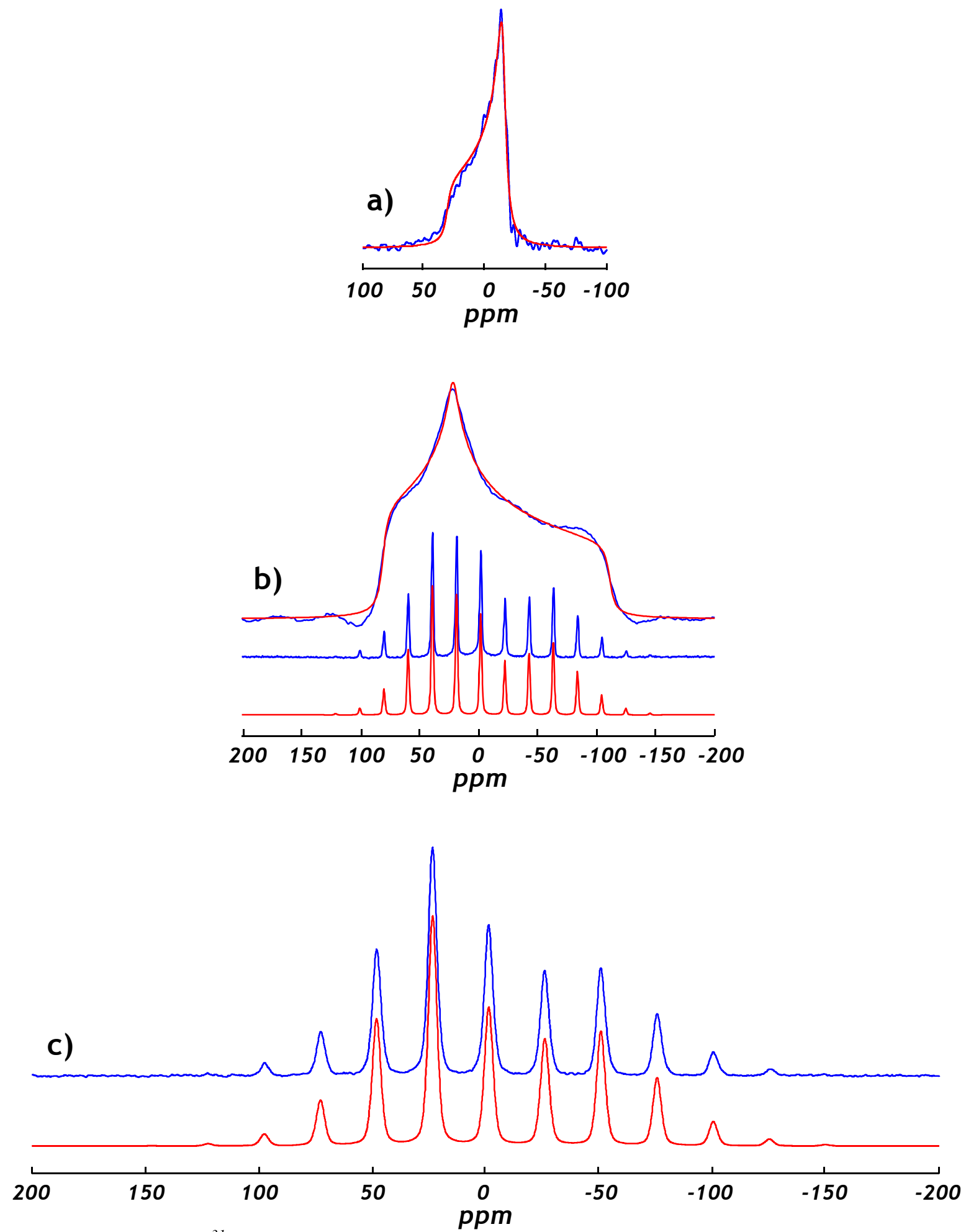

Figure S5: a) Blue: ${ }^{31} P$ static NMR spectrum of DPPC aqueous liposomes (no cross polarization). Red: DMFit simulation with a pure CSA lineshape $\left.\left(\Delta_{C S}=35.0 \mathrm{ppm}, \eta_{C S}=0.0\right) . b\right)$ Blue: ${ }^{31}$ P static and MAS (2.5 kHz) spectra of dry DPPC (no cross polarization). Red: their respective DMFit simulations with pure CSA lineshapes $\left(\Delta_{C S}=-110.0 \mathrm{ppm}, \eta_{C S}=0.6\right)$. c) Blue: ${ }^{31} P \mathrm{MAS}(3 \mathrm{kHz})$ spectrum of liposils (with ${ }^{1} \mathrm{H}^{31} \mathrm{P}$ cross polarization). Red: DMFit simulation with pure CSA lineshapes $\left(\Delta_{C S}=-99.5 \mathrm{ppm}, \eta_{C S}=0.6\right)$. 


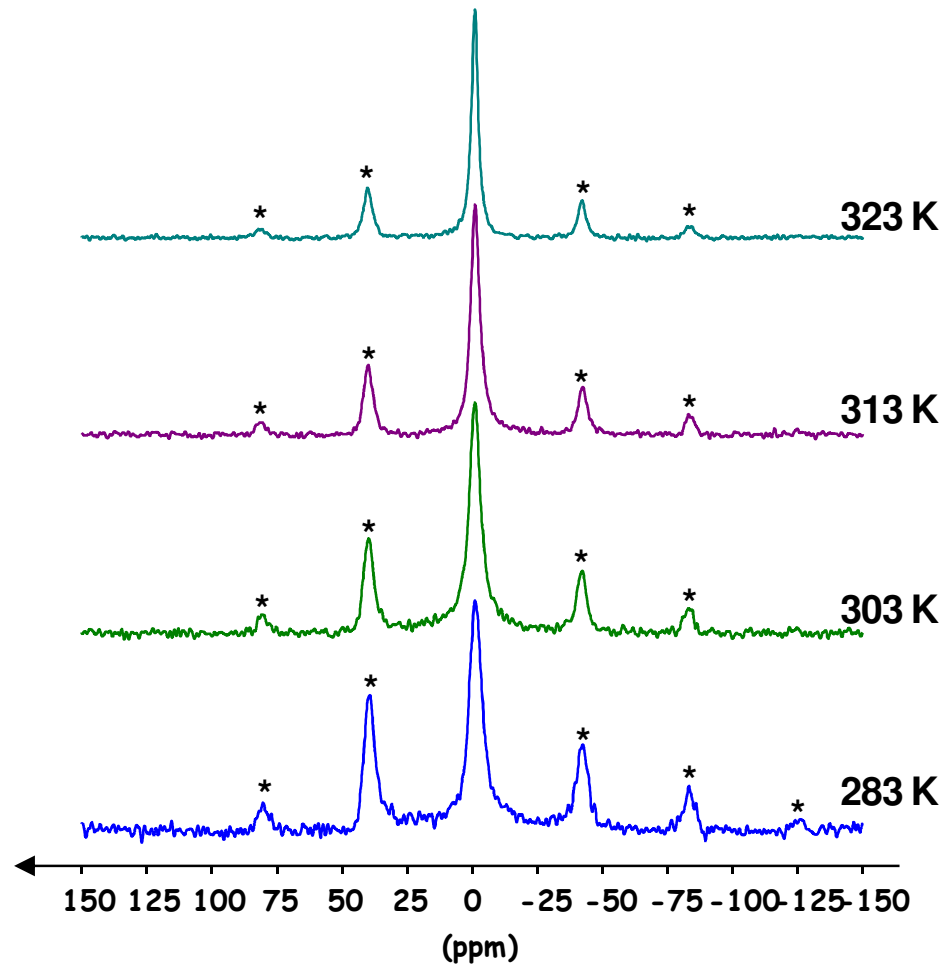

Figure S6: variable temperature ${ }^{31} \mathrm{P}$ MAS spectra of liposils $(5 \mathrm{kHz}$, without cross polarization). 


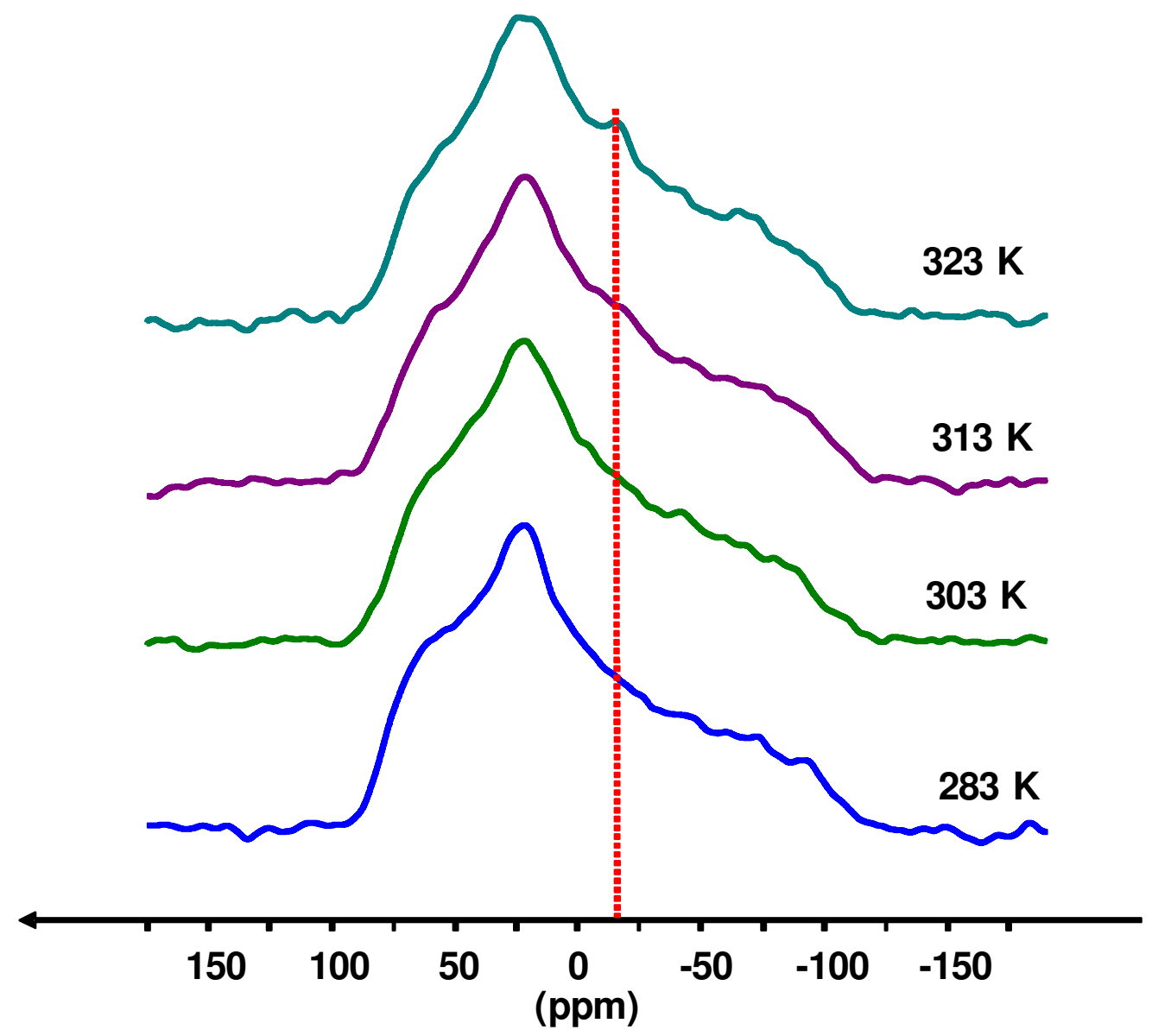

Figure S7: variable temperature ${ }^{31} P C P\left(t_{C P}=2 \mathrm{~ms}\right)$ static spectra of liposils (red dashed line: the main component of site 2 , as detected by direct ${ }^{31} P$ detection - see Figure 3). 


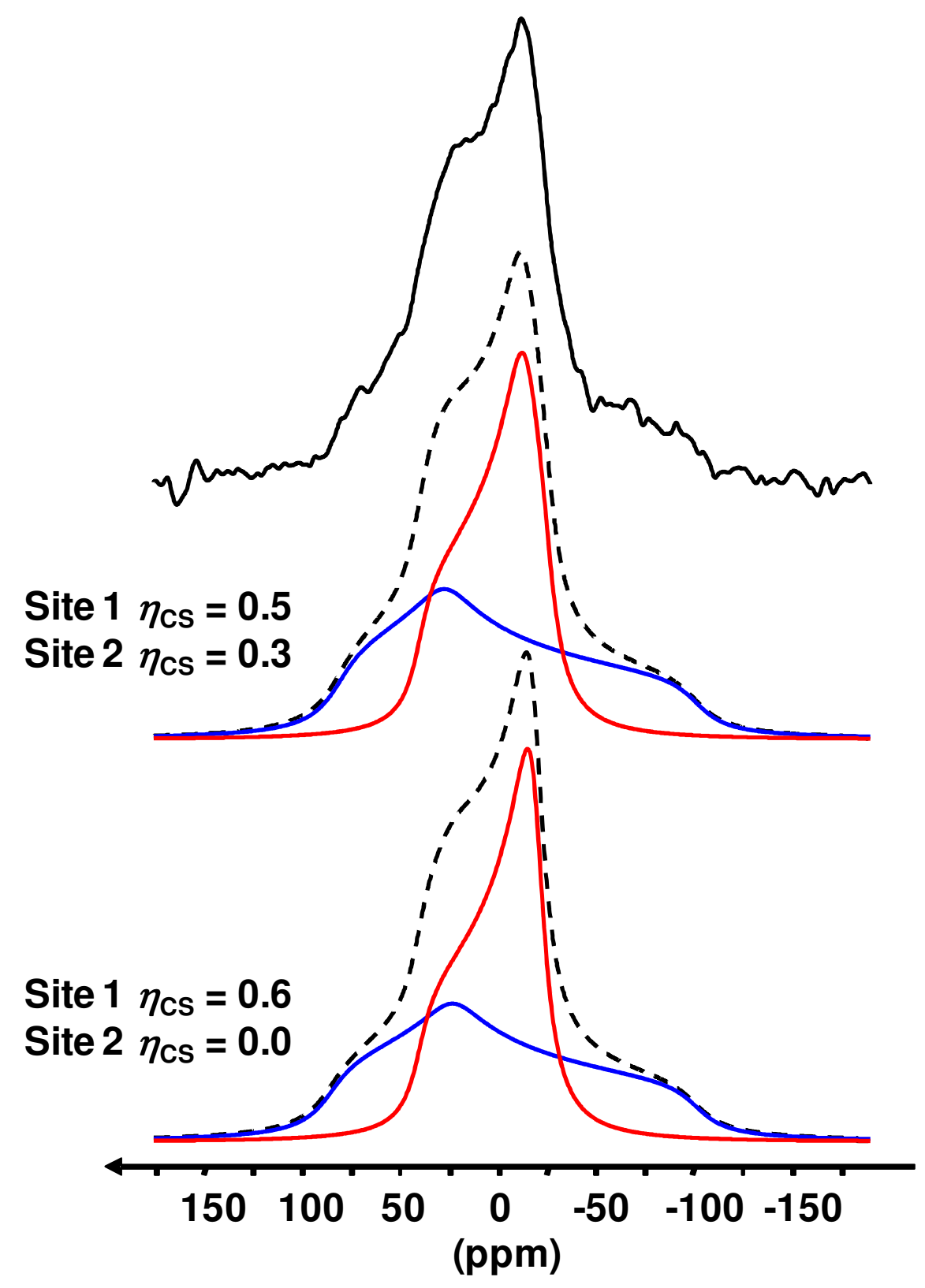

Figure S8: ${ }^{31} \mathrm{P}$ static spectrum of liposils at $\mathrm{T}=313 \mathrm{~K}$ (see also Figure $3 \mathrm{~b}$ ). Both sets of simulations correspond to $\eta_{C S}=0.5$ and 0.6 for site 1 in blue and $\eta_{C S}=0.3$ and 0.0 for site 2 in red. 


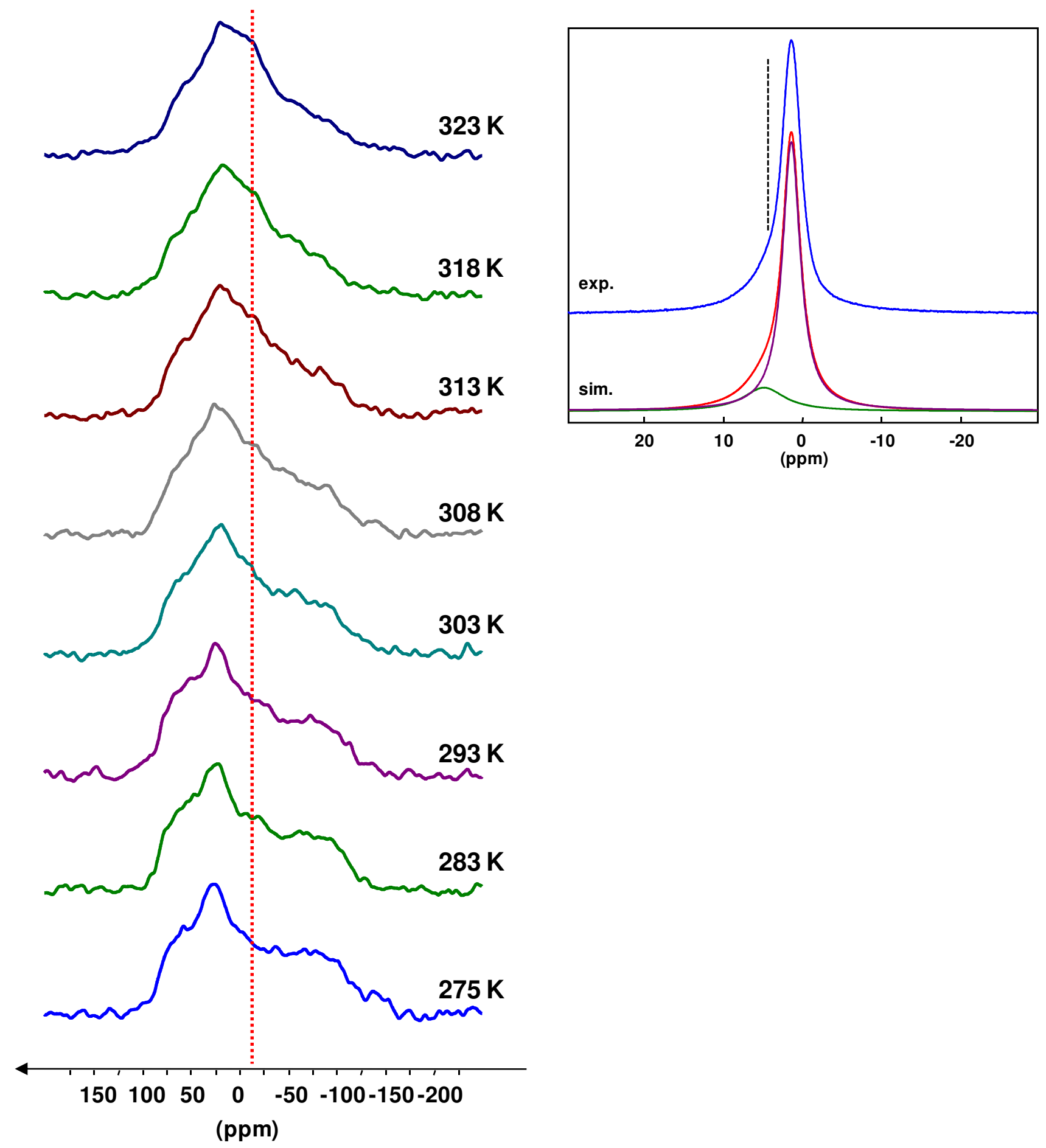

Figure S9: variable temperature ${ }^{31} P$ static spectra (without cross polarization) of dehydrated liposils (red dashed line: the main component of site 2 - see Figure $3 a$ ). Insert: static ${ }^{1} H$ NMR spectrum. Red line: simulation with 2 components corresponding to the DPPC molecules (aliphatic chains in purlple, and choline/glycerol neck/ethylene, in green). The $\mathrm{H}_{2} \mathrm{O}$ contribution (dashed line) is absent (see Figure S10). 


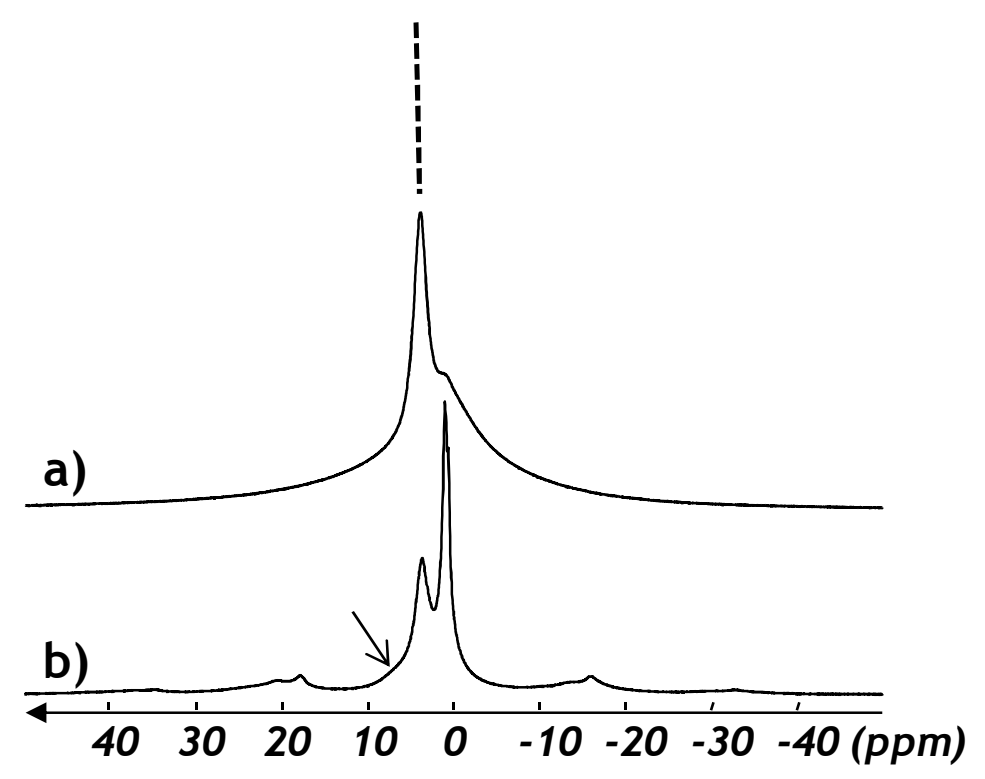

Figure S10: a) Static and b) MAS ( $\left.v_{M A S}=5 \mathrm{kHz}\right)$ single pulse ${ }^{1} \mathrm{H}$ spectra of liposils. The arrow indicates broad resonances at $\sim 7 \mathrm{ppm}$. The dashed line indicates the chemical shift of the $\mathrm{H}_{2} \mathrm{O}$ resonance. 




Figure S11: ${ }^{1} \mathrm{H}$ COSY NMR spectrum of DPPC in $\mathrm{CDCl}_{3}$ with assignment. 